\title{
The Impact of E-commerce Capabilities on Online Retailer Performance: Examining the Role of Timing of Adoption
}

\begin{abstract}
This study examines how the timing of the adoption of e-commerce capabilities affects the performance of online retailers. By applying a resource-based view and innovation diffusion theory, we examine capability adoption by the top 500 US online retailers over seven years period. We present how ecommerce capabilities differentially contribute to performance outcomes. Capabilities vary in the durability of benefit, with some providing earlier adopter benefits and others showing benefits later in their life cycles. We find that some capabilities reward later adopters, contrary to prior research. These results support that adoption timing is key to the understanding of the contribution of e-commerce capabilities to online retailer performance.
\end{abstract}

Keywords: E-commerce Capabilities, Innovation Diffusion Theory, Resource-based View, Online Retailer Performance 


\section{The Impact of E-commerce Capabilities on Online Retailer Performance: Examining the Role of Timing of Adoption}

\section{Introduction}

In the United States, e-commerce continues to grow at a faster rate than that by retail sales. In 2020 , total e-commerce sales grew by $14.5 \%$ compared with a $2.8 \%$ growth in total retail sales. ${ }^{1}$ Although large online retailers are dominant in terms of both sales and market share, estimates indicate that $>2$ million online retail outlets compete for consumer dollars in the ecommerce space. The convenience of online shopping and the technological advances that have improved performance and productivity have spurred the establishment of numerous online-only retailers and thus pushed traditional retailers to integrate e-commerce channels with their existing brick-and-mortar channels [1]. Regardless of their size, online retailers invest in the adoption of e-commerce capabilities ${ }^{2}$, leveraging technology to generate business value through the promotion and sale of products [2,3]. Through such investments, online retailers aim to increase their share of online sales by attracting shoppers to their websites, improving the online shopping experience, and converting website visitors into buyers [4-6].

Online customers have very low switching costs, and online retailers are consequently willing to spend considerable sums to retain existing customers and attract new ones [7]. Over the last decade, spending on e-commerce technology has more than doubled [8], and the annual growth rate between 2020 and 2027 is predicted to be $16.3 \%$ [9]. This spending aimed to improve the online retailer's ability to meet customer needs while improving financial performance. However, the quickly changing technology landscape makes it difficult for online

\footnotetext{
${ }^{1}$ https://www.census.gov/retail/mrts/www/data/pdf/ec_current.pdf

${ }^{2}$ Some prior literature has referred to e-commerce capabilities as first-order dimensions of a second-order ecommerce capability construct [2,3,39]. We use the term e-commerce capabilities to describe an existing basket of specific features or functionalities that retailers leverage to meet business process requirements in the online environment.
} 
retailers to isolate and assess the business value gained by investing in or adopting e-commerce capabilities [10]. Furthermore, as e-commerce undergoes rapid growth, the impact of the timing of capability adoption on business value remains unclear. Online retailers grapple with the uncertainty of whether to pursue early adoption of a capability to maximize the benefits or wait to see if a capability performs as expected.

In the present study, we examine the impact of investment in e-commerce capabilities on e-commerce performance. We also investigate the potential benefits associated with strategically timing the adoption of e-commerce capabilities. Prior research using the resource-based view suggests that investment in e-commerce capabilities can provide a greater competitive advantage when an organization makes strategic decisions on the adoption of e-commerce capabilities in line with the business processes [2,11]. Prior research also identifies and assesses four valuecreating e-commerce capabilities that are generally associated with improved online retailer performance: information, transaction support, interaction and customization, and infrastructure $[3,12,13]$. We focus on the adoption of these e-commerce capabilities because of their close association with specific business processes in the customer order life cycle [2].

The term "adoption" has been employed in information technology (IT) literature to signify the decision to purchase, develop, or use certain technological innovations [14]. We use the term "adopt" to signify an online retailer's acquisition of e-commerce functionality to provide e-commerce capabilities. Although our focus is on the theoretical construct of ecommerce capabilities, these capabilities "should be reflected in the functionalities of a company's Web site" [3, p. 279]. E-commerce functionality refers to the specific technologies implemented by online retailers and serves as an indicator of the adoption behavior of ecommerce capabilities [2]. 
The potential ease with which competitors can copy e-commerce capabilities makes the relationship between when a capability is adopted and how long it provides a relative advantage tenuous. Over time, a capability may change or be replaced by a newer one. In other cases, once a capability becomes almost universally implemented by other online retailers in similar ways, the competitive advantage associated with it fades. This situation suggests an additional concern on top of the decision to invest in e-commerce capabilities: when to invest. The very nature of digital technologies suggests that adopting e-commerce capabilities should not lead to long-term competitive advantage because competitors can identify and copy them easily [15]. However, a firm that adopts key e-commerce capabilities late or not at all may find itself at a competitive disadvantage. The commoditized nature of e-commerce capabilities means that online retailers must also determine the timing of adoption to maximize the competitive advantage they can gain from their investment. Furthermore, we anticipate that the rate of adoption for e-commerce capabilities across firms will likely approximate the diffusion curve for similar innovations. Online retailers that can properly time the adoption of certain e-commerce capabilities may be able to maximize their return on investment, thus achieving long-term benefits [16]. We posit that depending on how early or late in the capability's diffusion life cycle that adoption occurs, the online retailer may realize an early-mover advantage and obtain more enduring performance over time.

This study examines the association of investment in e-commerce capabilities with business value, measured as online retailer performance. Online retailers are particularly concerned about results related to sales and customer activity $[17,18]$. To achieve the objective of this study, we focus on three quantifiable performance measures: sales, unique monthly visitors, and total monthly visitors. Which e-commerce capabilities to invest in, as well as when 
to invest in them, become key concerns to drive an increased and sustained online retailer performance [19]. Consequently, our specific research questions are as follows:

1. Does the adoption of e-commerce capabilities enhance online retailer performance?

2. How does the timing of adoption of e-commerce capabilities affect online retailer performance?

3. Are there enduring benefits associated with earlier adoption of different ecommerce capabilities?

This research draws from secondary data collected from the Internet Retailers Top 500 Guide [20] to examine the relationship between specific e-commerce capabilities and key online retailer performance metrics (online sales and customer traffic). Our dataset allows us to directly compare performance measures across online retailers, including online-only and traditional brick-and-mortar retailers integrating e-commerce channels, as each retailer invests in ecommerce capabilities [21-23]. ${ }^{3}$ Prior research examines e-commerce capabilities as a single construct; however, we examine whether an online retailer's timing of the adoption of a particular e-commerce capability (e.g., early or late) has a durable effect on its performance. Our approach provides a more nuanced examination of e-commerce capabilities and their relationship to business value. We illustrate that not all investments in e-commerce capabilities equally contribute to business value, and the contributing investments may do so only initially, later, or throughout the life cycle of a capability.

\section{Background and Related Literature}

Research on whether an investment in information technologies (IT) provides business value is extensive (for a summary, see [24,25]). A continued area of focus in this literature is on

\footnotetext{
${ }^{3}$ Our data allow us to directly measure online sales performance, independent of overall sales performance through other mediums such as brick-and-mortar retail stores or call centers.
} 
IT capability development, which is defined as the ability to deploy and utilize IT resources in line with business processes [26,27]. From a resource-based view, an organization that can align IT capabilities with other organizational capabilities should be able to create a distinctive base of competitive advantage.

One of the critical problems with understanding the business value of IT is often the indirect connection between IT capabilities and firm financial performance [28,29]. Instead, recent studies focus on how the integration of specific IT capabilities with other organizational capabilities relates to business value. For example, IT integration capabilities, which enable more connections between organizations, facilitate a firm's capacity to absorb and desorb knowledge [30]. Big data analytics capabilities — defined as a firm's ability to capture, analyze, and gain insights from data - interact with information governance practices to enhance a firm's innovation capabilities [31]. Online marketing capabilities, including a firm's ability to use website tools such as search engine optimization (SEO), banner ads, and social media, interact with an understanding of customer characteristics to better convert website visitors to online customers [32].

The e-commerce literature mimics the broader IT literature on business value with mixed findings $[2,13,33]$. It describes the complexity of the relationship between e-commerce technology investment, e-commerce capabilities development, and firm performance [29]. In addition, this literature highlights the need to pursue e-commerce strategically to be effective [34], while considering e-commerce capabilities in tandem with other organizational, business, or IT resources [35] and accounting for the competitive dynamics associated with adoption and diffusion [1].

E-commerce capabilities reflect an organization's ability to leverage technology and 
website functionality to promote and sell products [2,3]. Thus, the relationship of e-commerce capabilities with business value is intricately tied to an organization's ability to support the business processes associated with the customer order life cycle $[2,13,29]$. Prior research offers several perspectives on how e-commerce capabilities provide value to the customer order process (see Table 1 for a summary). Several studies view e-commerce capabilities as encompassing both the human resource and technological capabilities that enable online customer interactions [13,36-37]. Other studies conceptualize e-commerce capabilities as being based on four broad components: information, transaction, customization, and back-end integration $[3,29,38]$.

However, despite recognition of the association between customer order activities and ecommerce capabilities, much of this research examines e-commerce capability as a single construct, overlooking the nuances associated with different e-commerce capabilities related to online retailer success.

\section{Table 1. Perspectives on E-commerce capabilities}

\section{E-commerce capabilities viewed as a multidimensional construct made up of multiple first- order dimensions \\ E-commerce capability metric is composed of four dimensions, measured with multiple functionality variables $[2,3,38,39]$ \\ 1. Information-provides useful facts about products/services \\ 2. Transaction-facilitates transactions online \\ 3. Interaction/customization - enables online interactions between a firm and its customers, and allows customers to customize their experience to personal preferences \\ 4. Backend integration/supplier connection - involves electronic links to integrate suppliers}

E-commerce capabilities consist of items measuring seven e-commerce technology resources [35]: interactivity, publishing, community, catalog, transaction, network, and user interface.

E-commerce capability is viewed as the ability to provide product and company information online and conduct transactions through an online store [40].

E-commerce front-end capability is viewed as encompassing customer interactions through information presentation, transactions, and customization, and is measured as the accumulation of difference between e-commerce resource inflow and depreciation [29]. 
E-commerce capabilities viewed as encompassing human resource and technological capabilities

E-commerce capability construct, composed of three dimensions, measured via survey [37]:

1. E-commerce management capability-ability to foresee and utilize e-commerce technologies

2. E-commerce technical capability - ability to deliver technical solutions efficiently

3. E-commerce talent capability_employees' knowledge and skills

Three core e-commerce capabilities measured via survey [36]:

1. IT governance - integrating IT efforts with business purpose

2. Business systems thinking - envisioning business processes enabling e-commerce

3. Relationship building — getting the business engaged in e-commerce issues

Internal and external capabilities that support online performance [13]:

1. IT skills (internal) - technology skills held by IT employees

2. Cost efficiency (internal) - ability to provide cost-effective, efficient operations over time

3. Market sensing (external) — ability to gather, interpret, and utilize market information

4. Brand management (external) — ability to develop and support strong brands

5. Customer service (external) — ability to provide strong customer service

\section{Theory and Hypothesis Development}

\subsection{Resource-Based View of E-Commerce Capabilities}

Our first research question focuses on whether the adoption of e-commerce capabilities

affects online retailers' performance. The resource-based view of the firm [41] suggests that organizations control and prioritize limited resources to enhance their e-commerce capabilities.

The application of these resources toward e-commerce capabilities may lead to improved performance $[35,42]$ or create rare and/or unique e-commerce capabilities [13]. To the degree that an organization can maintain these unique capabilities such that they are not copied, imitated, or otherwise acquired by their competitors, the organization may be able to generate long-term performance advantages over its competitors $[13,43,44]$.

Digitally derived capabilities alone will not deliver superior performance if a competitor can emulate or acquire them $[11,15]$ because any competitive advantage that they offer may be short term. Maintaining competitive benefits or obtaining any significant competitive advantage 
will often require continual investments to keep pace with rapid technological change and to maintain digital asset uniqueness relative to the competitors [39].

The resource-based view suggests that investment in and updates to an easily imitated digital capability can provide a competitive advantage over a previous capability or competitors; an advantage may also be gained when a firm can creatively align the investment with existing business processes $[2,11]$. Therefore, it is necessary to look beyond traditional indicators of investments (e.g., dollars expended) to assess IT resources and gauge the benefit of investment in digital resources [45], particularly in the online retail environment [46].

Zhu and Kraemer [3] identify four e-commerce capabilities associated with business value in e-business processes: information, transaction, interaction and customization, and infrastructure. ${ }^{4}$ The information capability provides a customer with useful information about different products and services available for sale on the website. The transaction capability facilitates transactions initiated by the customer to select, price, and/or pay for a product or service. Interaction and customization capabilities (hereafter, interaction) enhance the customer experience by capturing customer-specific information and using it to tailor the e-commerce shopping session to the user's unique needs. The infrastructure capability increases e-commerce effectiveness and efficiency by improving website speed, updating content, and making web pages and multimedia from third parties readily available to online customers, thereby improving customers' experience with the website.

Each of these four capabilities is reflected in e-commerce functionalities on the online retailer's website. Together, they support a unique business process associated with online retail

\footnotetext{
${ }^{4}$ Zhu and Kraemer [3] originally identified information, transaction, interaction, and supplier connection. We expand the notion of supplier connection with infrastructure to recognize a broader e-commerce capability that enhances the underlying functionality of the website for customers, suppliers, and other related parties. Supplier integration is likely to be more appropriate for manufacturing B2B websites as applied in Zhu and Kraemer [3].
} 
performance; therefore, each contributes to providing a competitive advantage [2]. E-commerce functionalities represent the technologies that facilitate website activities and support a wide range of customer interactions, website processes, and online retailer interactions with suppliers [3]. For example, the transaction capability is reflected in functionalities such as catalog quick order or express checkout. The interaction and customization capability are reflected in functionalities such as frequent buyer programs or website personalization.

Prior research refers to the adoption of e-commerce capabilities, but as explained above, capability describes an existing basket of specific features or functionalities. Similarly, when a firm invests in a capability, it creates or improves one or more unique and identifiable functionalities that together constitute the capability. This research bridges the theoretical construct of capabilities with what can be observed on firms' websites. Therefore, we focus on the adoption of functionalities as a proxy for what prior research refers to as the adoption of capabilities [1-3].

\subsection{Diffusion of Innovation}

Our second research question focuses on whether the timing of the adoption of ecommerce capabilities affects online retailers' performance. Diffusion of Innovation theory can be used to distinguish value creation through investment in e-commerce capabilities based on when online adoption takes place during the capabilities' diffusion life cycle. Therefore, this question focuses on the adoption decisions that intersect with established innovation diffusion life cycle benchmarks during our sample period [16].

Innovations in e-commerce follow a predictable life cycle. A firm recognizes a need or opportunity and adopts an innovation to meet that need. If competitors view the innovation as successful or desirable, they may copy and adopt the innovation for use in their own businesses. 
Such spread of innovation across a competitive landscape is referred to as the diffusion of innovation [1], and the diffusion of innovation can be examined as a function of the share of firms that have adopted that innovation.

Rogers' [16] five phases of adoption characterize firms by the point in time when they adopt a particular innovation during their life cycles (Figure 1). Early work in various technology adoption contexts suggests that firms that adopt innovations at different timepoints have different characteristics and motivations $[47,48]$. Innovators are the initial $2.5 \%$ of adopters that are willing to accept additional risks to be the first to use an innovation/idea/revolutionary concept. They see value in being an early adopter and believe the returns will outweigh any risks. Early adopters represent the next $13.5 \%$ of adopters. They are typically viewed as leaders; they accept change as part of doing business. Early adopters tend to use existing innovations that make a certain amount of risk associated with new technology acceptable. Early adopters use what was learned by the innovators earlier to manage the risk and increase the chances that innovations will be successfully integrated into their current business processes [48,49].

The next $34 \%$ are labeled as the early majority. This group will not adopt an innovation without some evidence of the benefits realized by earlier adopting firms. If the innovation creates a competitive advantage for early adopters, the innovation is copied. If not, the failure means the end of the new technology [49]. In general, this group is slightly more risk-averse than the early adopters and will wait until the early success mitigates the risk of investment in new technology but will act when the potential benefit of adoption is still clear [48].

The late majority represent the next $34 \%$ of adopters of innovation. This group is less optimistic about adoption and will choose to adopt only after the capability is widely adopted and is, therefore, a proven innovation. In general, this group is less likely than early adopters or 
the early majority to decide to invest based on perceived benefits to the existing business processes. Instead, the focus of the late majority is on maintaining technical parity with other organizations [48]. These adopters wait for technology to be widely accepted by other organizations and invest based on peer or market pressure.

Finally, laggards are the last $16 \%$ to adopt an innovation. This last group is very skeptical regarding innovations and sees adoption as a last resort. Frequently, investment in innovation is a matter of necessity for this group. In general, firms in this group are very conservative or reluctant to invest in new technology. Laggards may invest in innovation that is not perfectly compatible with existing operations and business processes but chooses to invest because survival depends on it [48].

These adoption group distinctions are relevant because they represent theoretical differences in adopting groups. These differences help define the value expected by these groups based on the timing of the adoption of a particular innovation in its diffusion life cycle. Because the diffusion life cycle helps to identify the degree to which innovation has already been adopted by competitors, it also suggests potential differences in the relative value and sustainability of the value that adopting a capability will provide to an online retailer.

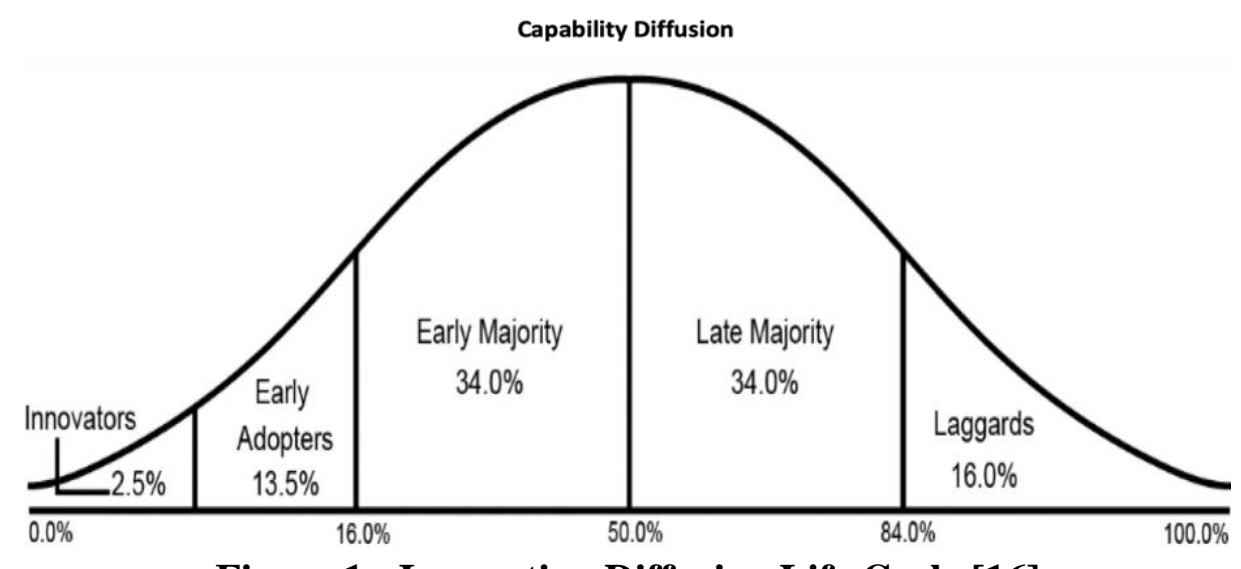

Figure 1 : Innovation Diffusion Life Cycle [16]

\subsection{Hypothesis Development}


As previously noted, online retailers invest in e-commerce capabilities in the hopes of encouraging sales or customer traffic to their websites [2,3]. Owing to their impact on underlying business processes, these capabilities are seen as a way to improve business outcomes and generate competitive advantage $[35,40]$. However, the resource-based view proposes that the means by which online retailers attempt to improve capabilities (here, the adoption of various ecommerce functionalities) is not a guarantee of increased performance due to the digital nature of these functionalities [41]. For a competitive advantage to persist, the functionalities that are associated with a capability [3] must be difficult for competitors to acquire, copy, or substitute [50]. Digital technologies may be highly imitable when made available on online retailer websites, leading to the prediction that the duration of competitive advantage from the adoption of online capabilities could be fleeting [11,15].

Barney [41] noted that resource heterogeneity may take various forms when developing a competitive advantage even when resources (functionalities) appear to be copiable or substitutable (not rare) across firms. In this case, the very knowledge or act of investment in functionality indicates a source of difference in the capability, leading to differential outcomes [42]. Therefore, according to the resource-based view, the decision to adopt e-commerce capabilities may indicate a source of at least an immediate or temporary competitive advantage in performance compared with competitors that did not make a similar adoption decision [35]. Prior research supports the view that organizations that adopt e-commerce capabilities generally enjoy superior performance relative to those that have not adopted them $[13,35,40]$. Our first hypothesis ignores the timing of adoption and focuses on whether having an e-commerce capability leads to greater performance outcomes. We, therefore, hypothesize a general benefit associated with the adoption of e-commerce capabilities, formally stated as: 


\section{H1: The adoption of e-commerce capabilities will be positively related to online retailer}

performance.

Although the competitive advantage associated with e-commerce investment may be transient due to its digital nature, the diffusion of innovation theory predicts that online retailers that adopt capabilities earlier in the diffusion life cycle may benefit from an early-mover advantage (EMA) and obtain the greatest performance from investment in e-commerce capabilities [16,51]. However, given the low switching costs associated with e-commerce, obtaining EMA may be less likely in an e-commerce setting than in physical marketplaces [52]. The resource-based view suggests that EMA in this environment is likely to be associated with the ability of early-adopting online retailers to strategically adopt and accumulate resources that will best enhance their existing e-commerce capabilities and to provide a unique resource that others do not yet have [53]. Based on Rogers' categories of adopters [16], online retailers that are earlier adopters of e-commerce capabilities are more likely to be deliberate in their investment in innovation, choosing to adopt capabilities that are closely aligned with their existing business capabilities and can be easily integrated [2]. In contrast, online retailers that adopt capabilities later are more likely to be influenced by external factors and perceptions of the benefits achieved by earlier adopters, rather than strategic alignment with current capabilities [47]. Therefore, we would expect early adopters to obtain a greater benefit from the initial investment in e-commerce capabilities, compared with the late adopter firms. We hypothesize:

H2: Early adopters of e-commerce capabilities will exhibit greater performance outcomes compared to performance outcomes of later adopters.

Under certain conditions, some e-commerce capabilities may provide longer-lasting benefits over time and throughout the diffusion cycle. For example, if customers expect a particular capability as the norm, they may penalize online retailers that have not yet adopted it. 
This situation is also true when retailers further develop an existing e-commerce capability through the adoption of new e-commerce functionalities and continue to gain performance returns. The resource-based view suggests that investment in e-commerce capabilities that are strategically integrated with existing business processes should provide the greatest source of competitive advantage [2].

Online retailer performance is associated with the ability of an e-commerce site to attract customers and provide an experience that will encourage both initial sales and repeat visits to the site. Extant literature documents the need for e-commerce capabilities that provide comprehensive and high-quality product information $[7,54,55]$. Owing to their role in supporting website visitors' information search activities, e-commerce functionalities associated with the information capability are highly visible and can easily be copied by competitors. As previously noted, we expect that the copying of e-commerce functionalities by rival online retailers would serve to diminish any unique performance advantage enjoyed by earlier adopters of e-commerce functionality. This outcome should be particularly true for functionalities associated with information capability, as customers now have more options from which to collect product information.

Transaction capabilities facilitate customers' efforts to select, price, and pay for a product or service. Prior literature suggests that the associated functionalities, which provide transaction task-relevant cues, are conducive to promoting increased online retailer performance [12]. Similar to information capabilities, the functionalities associated with transaction capabilities are highly visible and can be easily imitated by other firms. Continued adoption of transaction capabilities should provide a relative advantage over a firm's existing set of e-commerce capabilities, but the external-facing nature of the business process they support may prevent 
long-term competitive advantage. Over time, other online retailers would be expected to copy and adopt the functionalities associated with transaction capabilities, especially if early-adopting online retailers are seen to be gaining a competitive advantage by adopting them $[11,15]$.

Infrastructure capabilities enhance customer experience by increasing the efficiency and effectiveness of e-commerce business processes. Adoption of infrastructure capabilities is positively related to organizational performance owing to their influence on value-producing business processes $[2,56]$. Although functionalities associated with infrastructure capabilities are less visible externally than those reflecting information or transaction capabilities, infrastructure capabilities have been identified as one of the easier types to copy [42].

As the adoption of new information, transaction, and infrastructure capabilities increases, the innovation loses its uniqueness, resulting in less performance advantage between businesses that have adopted the capabilities and those that have not. If early-adopting online retailers are seen to be gaining a competitive advantage, other online retailers are expected to copy and adopt these capabilities over time $[11,15]$. Thus, we expect the performance advantage to decline over time, stated formally as:

\section{H3a: The positive effect of information, transaction, and infrastructure capabilities on} online retailer performance will diminish over time.

Interaction capabilities use customer-specific information to tailor e-commerce experiences to meet each customer's unique needs. Because functionalities associated with interaction capabilities are visible, diffusion of innovation theory (DOI) suggests that the value from the adoption of this capability should diminish over time as additional online retailers implement their functionalities to support interaction capability. However, given that this capability is intended to create durable customer loyalty toward specific websites, online retailers adopting them early should continue to experience a competitive advantage, even as competing retailers 
adopt the same underlying functionalities [57,58]. Research suggests that interaction capabilities enhance customer engagement and loyalty to a firm [38]. The combination of customer relationship business processes and interaction functionalities creates a unique resource that cannot easily be imitated by later adopting online retailers. Unlike other types of e-commerce capabilities, switching costs associated with interaction capabilities are higher because earlyadopting online retailers get more time to collect personalized information and develop a relationship with a customer. Early adopters should retain a competitive EMA, even as the capability diffuses [18]. Thus, we hypothesize:

H3b: The positive effect of interaction capabilities on online retailer performance will persist over time.

\section{Sample Construction}

\subsection{Data}

We obtain data for the largest 500 internet retailers identified in the Internet Retailer's Top 500 Guide [20]. Each year, the publisher makes available an online database that includes the largest 500 online retailers in the United States and Canada based on self-reported survey responses from each of the e-commerce companies. The database includes e-commerce-specific performance metrics by the company including annual sales, average unique monthly visitors, and average total monthly visitors. In addition to performance results, the Internet Retailer's Top 500 Guide also indicates the e-commerce functionalities offered by each company that year [20]. The existing e-commerce functionalities represent the company's adopted e-commerce capabilities.

Our sample of online retailers is limited to e-commerce sites in the United States and Canada, including pure online retailers and traditional brick-and-mortar retailers with ecommerce channels. A firm voluntarily reports when it has invested in functionality to support e- 
commerce capabilities. The Internet Retailer's Top 500 Guide dataset includes 137 such functionalities during the study period, though the data are not collected on all functionalities every year [20]. Therefore, we limit our analysis to functionalities (associated with our ecommerce capabilities of interest) reported every year during 2007-2011. This results in $44 \mathrm{e}-$ commerce functionalities, which we elaborate on in an online appendix. ${ }^{5}$ We later expand our sample to include more years $(2006,2012)$ to include performance metrics for the years before and after functionality adoption. New online retailers are added each year and others drop off the list of the top 500, resulting in an unbalanced panel. ${ }^{6}$ Panel data offer several advantages over cross-sectional or time-series data. First, by blending both inter-firm and intra-firm differences over time, panel data provide a greater capacity for capturing the complexity of firm behavior, lessening the impact of omitted variables, thereby improving the efficiency of the estimates. Our final sample includes 3,500 firm years.

We also collect our three online retailer performance measures reported by Internet Retailer's Top 500 Guide: annual online sales, average unique monthly visitors, and average total monthly visitors [20]. Sales captures annual online sales for the online retailer. Total Monthly Visitors captures each time a shopper visits the online retailer's website, and Unique Monthly Visitors captures only the first-time shoppers visit the website each month [59-61]. Each company self-reports one value per year for each performance measure; thus, there is one firm-year observation for each company covered in the database.

\footnotetext{
${ }^{5}$ Three functionalities are not reported for the full sample period of 2006-2012; personalization is reported for 20082012, and deferred payment and PayPal express checkout are reported for 2007-2011.

${ }^{6}$ As a robustness test, in untabulated results we complete all analyses on a balanced panel of 260 firms that are present in the entire seven-year sample period. Results are statistically similar and robust to this specification for all tests of hypotheses. This provides strong evidence that results are not driven by firms entering or leaving the sample during the sample period.
} 
We recognize that selection bias may be present due to the focus on the top 500 Internet firms. However, we address this concern by using a sample of firms across a large number of industries. Based on the US Department of Commerce estimates of annual e-commerce sales, our sample coverage of e-commerce sales ranges from $82 \%$ to $93 \%$ of total online sales each year during our sample period. Our smallest firm has US\$4.4 million in average annual sales. Other published studies have used the Internet Retailers Top 500 database [62-65]. In the absence of publicly available multi-year data for the universe of small websites that exist, these data for the top 500 online retailers are more generalizable than data that use within-firm analysis [22,66-68] or a small sample of firms in one industry [69].

\subsection{E-commerce Functionalities and Capabilities}

We begin our analysis by assigning each of the 44 e-commerce functionalities to one of the four value-creating e-commerce capabilities previously discussed: information, transaction, interaction, and infrastructure [3]. To validate the assignment, we employed five raters to independently assess and categorize the 44 functionalities. Each rater was provided with the 44 e-commerce functionalities, a definition of the functionality, and the four value-creating ecommerce capabilities. Each rater was then instructed to assign each function to a capability. We did not provide individuals with suggested assignments or the anticipated number of functionalities per capability. As a result of the assignment, an interrater reliability value was determined for the entire set of functionalities and capability matches. The results indicated significant agreement (Fleiss Kappa of 0.67), considering particularly the use of five raters assessing 44 functionalities into four capabilities.

The next step in our analysis is to observe the diffusion process for all 44 e-commerce functionalities and identify the functionalities whose level of adoption crosses from one phase to 
the next in the innovation diffusion life cycle. We report the 11 functionalities that changed from 2006-2012 and note that personalization crossed two phases (see Table 2 for a list of the functionalities changing phase in this analysis). We observe the phase change from early adoption to the early majority (EA-EM) for making product comparisons and syndicated content representing information capability; deferred payment and PayPal express checkout representing transaction capability, and frequent buyer program and personalization representing interaction capability. We observe the phase change from early majority to the late majority (EM-LM) for catalog quick order representing transaction capability; personalization representing interaction capability; and content delivery representing infrastructure capability. Finally, we observe the phase change from late majority to laggard (LM-LAG) for Customer Relationship Management (CRM), e-commerce platform, and web performance monitor, representing infrastructure capability. Our analyses focus on these functionalities and their relationships with online retailer performance outcomes at the point in time when their level of adoption changed phase in the innovation diffusion life cycle. 
Table 2. E-commerce Functionalities with Diffusion Phase Changes

\begin{tabular}{|c|c|c|c|}
\hline $\begin{array}{l}\text { Functionalities by E- } \\
\text { Commerce Capability }\end{array}$ & $\begin{array}{c}\text { Observed Range } \\
\text { of Adoption } \\
\text { Levels }\end{array}$ & Phase Change Description & $\begin{array}{c}\text { Before } \\
\text { Diffusion } \\
\text { (Early Phase) }\end{array}$ \\
\hline
\end{tabular}

\begin{tabular}{|c|c|c|c|c|}
\hline \multicolumn{5}{|l|}{ Information Capability } \\
\hline Product comparisons & $11 \%-24 \%$ & Early Adopter to Early Majority & 2006 & 2007-2012 \\
\hline Syndicated content & $14 \%-21 \%$ & Early Adopter to Early Majority & 2006 & 2007-2012 \\
\hline \multicolumn{5}{|l|}{ Transaction Capability } \\
\hline Catalog quick order & $32 \%-67 \%$ & Early Majority to Late Majority & 2006-2011 & 2012 \\
\hline Deferred payment & $11 \%-21 \%$ & Early Adopter to Early Majority & 2007 & 2008-2011 \\
\hline PayPal express checkout & $14 \%-20 \%$ & Early Adopter to Early Majority & 2007 & 2008-2011 \\
\hline \multicolumn{5}{|l|}{ Interaction Capability } \\
\hline Frequent buyer program & $16 \%-26 \%$ & Early Adopter to Early Majority & 2006 & 2007-2012 \\
\hline Personalization (EA-EM) & $16 \%-30 \%$ & Early Adopter to Early Majority & 2008 & 2009-2011 \\
\hline Personalization (EM-LM) & $47 \%-56 \%$ & Early Majority to Late Majority & 2009-2011 & 2012 \\
\hline \multicolumn{5}{|l|}{ Infrastructure Capability } \\
\hline Content delivery & $48 \%-64 \%$ & Early Majority to Late Majority & 2006-2007 & 2008-2012 \\
\hline$C R M$ & $70 \%-100 \%$ & Late Majority to Laggard & 2006-2008 & 2009-2012 \\
\hline E-commerce platform & $82 \%-94 \%$ & Late Majority to Laggard & 2006 & 2007-2012 \\
\hline Web performance monitor & $83 \%-86 \%$ & Late Majority to Laggard & 2006-2009 & 2010-2012 \\
\hline
\end{tabular}




\section{Empirical Model and Results}

\subsection{Empirical Model}

We use regression analysis to test our three hypotheses and begin with the following model:

$$
\begin{aligned}
\ln \left(\text { Outcome }_{i t}=\right. & \beta_{0}+\beta_{1} \text { EcomFunctionality }_{i t}+\beta_{2} \ln \left(\text { Size }_{i t}+\beta_{3} \text { Online }_{i}+\sum_{j=1}^{14} B_{4} \text { Category }_{t}^{j}\right. \\
& + \text { Firm }_{i}+\mathrm{e}_{i t}
\end{aligned}
$$

where we measure the dependent variable, Outcome, with our three performance measuressales, unique monthly visitors, and total monthly visitors for firm $i$ in year $t$ in category $j{ }^{7} \mathrm{We}$ use the natural log transformation for each dependent variable to correct for heteroskedasticity. We replace EcomFunctionality with each of the 11 functionalities whose adoption moved from one diffusion phase to the next, as previously discussed. EcomFunctionality is a dummy variable, taking on a value equal to one when the firm adopts a particular functionality, and zero otherwise. In our analysis, once a firm adopts a functionality, it always has the functionality. In some cases, the adoption may have taken place prior to 2006. For these functionalities, we assume adoption in 2006, the first year of our data collection. We control for the size of the firm (Size). We do not have access to additional firm-level data for the private companies or specifically isolated for the online segments of public companies in our sample. Thus, we control for size using online sales, except when the dependent variable is sales and then we use total monthly visitors. We control for the self-reported primary merchandise category of the firm (Category), and also include firm fixed effects. ${ }^{8}$ For the merchandise category, we use the online

\footnotetext{
${ }^{7}$ Each year, companies in the sample report their annual average for monthly unique and total website visitors to the Internet Retailers Top 500 Guide [20]. As such, we have one firm-year observation for each company in the sample for its average monthly unique visitors and its average monthly total visitors for the year.

${ }^{8}$ The Hausman test rejects the use of the random effects model in all the regressions in this paper.
} 
retailer's main product market identified in the Internet Retailer's Top 500 Guide [20]. Table 3 summarizes these 15 merchandise categories for our sample.

\section{Table 3.}

\section{Internet Retailer's Top 500 Guide [20] Merchandise Categories}

\begin{tabular}{lr} 
Merchandise Category & Firm-Years \\
\hline Apparel/Accessories & 837 \\
Automotive Parts/Accessories & 33 \\
Books/Music/Video & 194 \\
Computers/Electronics & 368 \\
Flowers/Gifts & 87 \\
Food/Drug & 159 \\
Hardware/Home Improvement & 169 \\
Health/Beauty & 183 \\
Housewares/Home Furnishings & 348 \\
Jewelry & 91 \\
Mass Merchant & 220 \\
Office Supplies & 119 \\
Specialty/Non-Apparel & 368 \\
Sporting Goods & 205 \\
Toys/Hobbies & 119 \\
Total & 3,500 \\
\hline
\end{tabular}

We also control for a firm's exclusive online presence (Online).${ }^{9}$ Online is an indicator variable, which equals one when a firm operates exclusively as an online business. Other online firms also have a significant brick-and-mortar presence and are designated with a zero value. Such firms are referred as click-and-mortar firms in Table 4.

\subsection{Descriptive Statistics}

We report descriptive statistics in Table 4, Panel A for our three performance outcomes (e.g., sales, unique monthly visitors, and total monthly visitors) and the 11 functionalities that

\footnotetext{
${ }^{9}$ Table 4 shows significant differences between online-only firms and brick-and-mortar firms with significant ecommerce activity. We include Online as a control variable in our regressions.
} 
experienced a diffusion phase change. We also present correlation statistics for the $11 \mathrm{e}-$ commerce functionalities analyzed in this study (Table 4, Panel B). In general, correlations are low, with most $\leq 0.10$, and none are statistically significant at conventional levels.

We report descriptive statistics for the total sample, online sellers that only sell online, and sellers that have both online and brick-and-mortar outlets (i.e., click-and-mortar) to be fully transparent regarding any differences between the type of firm sales structure. The t-test column reports statistical significance when the means between the two subgroups are statistically different. While average sales are not significantly different for online-only versus click-andmortar, online retailer sales vary dramatically across our online-only sample. Mean sales for the total sample are US $\$ 279$ million but range from US\$4.4 million to US\$48 billion. The top 250 online retailers represent $95 \%$ of sales for our sample, and Amazon.com represents more than $21 \%$ of the online sales among companies in our data. Further, sales in the online-only sample grew 121\% from 2006 to 2012 compared with only $42 \%$ growth registered for the click-andmortar hybrids (untabulated). Click-and-mortar hybrids have more unique and total monthly visitors, and the results are statistically significant.

We also observe heterogeneity in the adoption of e-commerce capability in online-only versus click-and-mortar hybrids. Compared with online-only firms, click-and-mortar firms have more functionalities representing the information and interaction capabilities, and the catalog quick order functionality represents the transaction capability. 
Table 4 Panel A: Summary Statistics

\begin{tabular}{|c|c|c|c|c|c|c|c|}
\hline \multirow[b]{2}{*}{ Variables } & \multicolumn{2}{|c|}{$\begin{array}{l}\text { Total sample } \\
(\mathrm{N}=3,500)\end{array}$} & \multicolumn{2}{|c|}{$\begin{array}{l}\text { Online only } \\
(\mathrm{N}=2,032)\end{array}$} & \multicolumn{2}{|c|}{$\begin{array}{l}\text { Click-and-Mortar } \\
\quad(\mathrm{N}=1,468)\end{array}$} & \multirow[b]{2}{*}{$\mathrm{t}$-test } \\
\hline & Mean & SD & Mean & SD & Mean & SD & \\
\hline Sales (US\$ millions) & 279 & 1,690 & 242 & 2,070 & 330 & 961 & \\
\hline Unique monthly visitors (millions) & 2.04 & 5.33 & 1.57 & 4.79 & 2.68 & 5.94 & $* * *$ \\
\hline Monthly visitors (millions) & 5.21 & 23.2 & 4.16 & 20.6 & 6.65 & 26.3 & $* * *$ \\
\hline \multicolumn{8}{|l|}{ Variables } \\
\hline \multicolumn{8}{|l|}{$\overline{\text { Information Capability }}$} \\
\hline Product comparisons & 0.26 & & 0.24 & & 0.27 & & $*$ \\
\hline Syndicated content & 0.22 & & 0.21 & & 0.25 & & $* *$ \\
\hline \multicolumn{8}{|l|}{ Interaction Capability } \\
\hline Frequent buyer program & 0.31 & & 0.26 & & 0.38 & & $* * *$ \\
\hline Personalization & 0.39 & & 0.37 & & 0.41 & & $* *$ \\
\hline \multicolumn{8}{|l|}{ Transaction Capability } \\
\hline Catalog quick order & 0.38 & & 0.36 & & 0.4 & & $* *$ \\
\hline Deferred payment & 0.18 & & 0.21 & & 0.15 & & $* * *$ \\
\hline PayPal express checkout & 0.21 & & 0.3 & & 0.08 & & $* * *$ \\
\hline \multicolumn{8}{|l|}{ Infrastructure Capability } \\
\hline Content delivery & 0.63 & & 0.67 & & 0.58 & & $* * *$ \\
\hline CRM & 0.81 & & 0.83 & & 0.78 & & $* * *$ \\
\hline E-commerce platform & 0.94 & & 0.94 & & 0.95 & & \\
\hline Web performance monitor & 0.76 & & 0.81 & & 0.69 & & $* * *$ \\
\hline
\end{tabular}


Table 4 Panel B: Correlations for E-Commerce Functionalities

\begin{tabular}{|c|c|c|c|c|c|c|c|c|c|c|c|c|}
\hline & & $(1)$ & (2) & (3) & (4) & $(5)$ & $(6)$ & (7) & $(8)$ & (9) & $(10)$ & $(11)$ \\
\hline (1) & Product comparisons & 1.00 & & & & & & & & & & \\
\hline (2) & Syndicated content & 0.25 & 1.00 & & & & & & & & & \\
\hline (3) & Catalog quick order & $(0.01)$ & 0.02 & 1.00 & & & & & & & & \\
\hline (4) & Deferred payment & 0.20 & 0.16 & 0.11 & 1.00 & & & & & & & \\
\hline (5) & PayPal express checkout & 0.04 & 0.10 & $(0.10)$ & 0.17 & 1.00 & & & & & & \\
\hline (6) & Frequent buyer program & 0.10 & 0.15 & 0.07 & 0.08 & $(0.05)$ & 1.00 & & & & & \\
\hline (7) & Personalization & 0.10 & 0.10 & 0.02 & 0.06 & 0.10 & 0.08 & 1.00 & & & & \\
\hline (8) & Content delivery & 0.10 & 0.04 & $(0.00)$ & 0.09 & 0.13 & 0.02 & 0.20 & 1.00 & & & \\
\hline (9) & CRM & 0.08 & 0.07 & 0.03 & 0.02 & 0.09 & $(0.04)$ & 0.19 & 0.23 & 1.00 & & \\
\hline (10) & E-commerce platform & $(0.02)$ & 0.05 & $(0.02)$ & $(0.03)$ & 0.01 & 0.01 & 0.01 & 0.01 & 0.07 & 1.00 & \\
\hline (11) & Web performance monitor & 0.02 & 0.09 & 0.09 & 0.10 & 0.12 & 0.04 & 0.17 & 0.35 & 0.24 & 0.06 & 1.00 \\
\hline
\end{tabular}

Notes: Panel A reports descriptive statistics for the performance outcome measures and functionalities grouped by e-commerce capability. The first column reports the full sample $(\mathrm{N}=3,500)$. The second column reports the subsample of online-only companies $(\mathrm{N}=2,032)$. The third column reports companies that sell online and in a physical brick-and-mortar location $(\mathrm{N}=1,468)$. The t-test reports statistical significance for the difference in means between the two subsamples. ***,**, and * denote statistical significance at the $0.01,0.05$, and 0.10 levels, respectively. Panel B presents correlations between e-commerce functionality variables. We define all variables in Appendix A. 


\subsection{Results for the Adoption of E-Commerce Capabilities on Online Retailer Performance}

To test H1, we augment the abovementioned model (1) to include all functionalities representing each of the four e-commerce capabilities examined, as defined by Zhu and Kraemer [39] (i.e., information, transaction, interaction, and infrastructure). Specifically, we use model (1) and replace the variable EcomFunctionality with Capability, which is a firm-time varying matrix of functionalities in a particular e-commerce capability. The number of coefficients varies as the number of functionalities within each capability changes. All other variables are previously defined for equation (1). This specification permits us to simultaneously test the effect of the individual functionality and also control for other functionalities within the same capability. ${ }^{10,11}$ For example, the regression for information capability includes product comparisons and syndicated content functionalities in the same regression. Our model specification for $\mathrm{H} 1$ is:

$$
\begin{aligned}
\ln \left(\text { Outcome }_{i t}=\right. & \beta_{0}+\sum_{j=1}^{c} B_{1} \text { Capability }_{i t}+\beta_{2} \ln \left(\text { Size }^{\mathrm{j}} \mathrm{j}_{i t}+\beta_{3} \text { Online }_{i}+\sum_{j=1}^{14} B_{4} \text { Category }_{t}^{j}\right. \\
& + \text { Firm }_{i}+\mathrm{e}_{i t}
\end{aligned}
$$

where $c \epsilon\{2,3,4\}$, depending on the number of functionalities in each capability. ${ }^{12}$

We include all firms in the regression, including early adopters, late adopters, and nonadopters for each underlying functionality representing the capability. While the full sample period is 2006-2012, data for every transaction and interaction capability is only available for 2007-2011, which reduces the sample size to 2,500 (see Table 2 and notes for Tables 5-7). We predict a positive and significant coefficient for each e-commerce functionality, supporting the idea that adoption of the functionality is associated with a positive performance outcome. Online

\footnotetext{
${ }^{10} \mathrm{We}$ also test each functionality separately and results are robust to both specifications.

${ }^{11}$ To address concerns of multicollinearity between the functionalities we ran variance inflation factors (VIFS) for all regressions and all VIFs are below 2.

${ }^{12} c=2$ for information capability and interaction capability, $c=3$ for transaction capability, and $c=4$ for infrastructure capability.
} 
retailer performance includes sales, unique monthly visitors, and total monthly visitors. We present regression results for our three performance-dependent variables in Tables 5-7, respectively. Each column presents regression results for the underlying functionalities for each e-commerce capability.

In Table 5, where the dependent variable is $\ln ($ Sales $)$, coefficients for all functionalities related to information and infrastructure capabilities (columns (1) and (4)) are positive and statistically significant. We also observe positive and statistically significant coefficients for PayPal express checkout (transaction) and personalization (interaction). Our results in Table 5 generally support $\mathrm{H} 1$ and show that e-commerce capabilities, as indicated by their associated functionalities, have a positive association with online sales.

We generally cannot support $\mathrm{H} 1$ when we use $\ln$ (Unique monthly visitors) as the dependent variable because most coefficients are statistically insignificant and a few coefficients are negative (Table 6). However, when we use $\ln ($ Total monthly visitors) as our dependent variable, we find some support for H1 (Table 7). Specifically, coefficients are positive and statistically significant for one functionality associated with information capability (syndicated content), one functionality associated with interaction capability (frequent buyer program), and two functionalities associated with infrastructure capability (content delivery and web performance monitor). Overall, our results suggest that firms that have these functionalities have higher sales and, in some cases, have more total visitors. E-commerce functionalities associated with the transaction capability do not appear to have a statistically significant impact on performance outcomes. The result for higher total visitors may suggest that these capabilities support increased repeat or loyal customers as opposed to attracting new unique customers. 
Table 5. The Impact of E-commerce Capabilities on Sales

\begin{tabular}{|c|c|c|c|c|}
\hline VARIABLES & $(1)$ & $(2)$ & (3) & (4) \\
\hline \multicolumn{5}{|l|}{ Information Capability } \\
\hline \multirow[t]{2}{*}{ Product comparisons } & $0.14 * * *$ & & & \\
\hline & $(0.02)$ & & & \\
\hline \multirow[t]{2}{*}{ Syndicated content } & $0.10 * * *$ & & & \\
\hline & $(0.03)$ & & & \\
\hline \multicolumn{5}{|l|}{ Transaction Capability } \\
\hline \multirow[t]{2}{*}{ Catalog quick order } & & 0.01 & & \\
\hline & & $(0.03)$ & & \\
\hline \multirow[t]{2}{*}{ Deferred payment } & & 0.03 & & \\
\hline & & $(0.03)$ & & \\
\hline PayPal express checkout & & $\begin{array}{c}0.14 * * * \\
(0.03)\end{array}$ & & \\
\hline \multicolumn{5}{|l|}{ Interaction Capability } \\
\hline Frequent buyer program & & & $\begin{array}{c}0.00 \\
(0.04)\end{array}$ & \\
\hline Personalization & & & $\begin{array}{c}0.22 * * * \\
(0.02)\end{array}$ & \\
\hline \multicolumn{5}{|l|}{ Infrastructure Capability } \\
\hline Content delivery & & & & $\begin{array}{c}0.15 * * * \\
(0.03)\end{array}$ \\
\hline \multirow[t]{2}{*}{$C R M$} & & & & $0.22 * * *$ \\
\hline & & & & $(0.02)$ \\
\hline \multirow[t]{2}{*}{ E-commerce platform } & & & & $0.08 * *$ \\
\hline & & & & $(0.03)$ \\
\hline \multirow[t]{2}{*}{ Web performance monitor } & & & & $0.07 * *$ \\
\hline & & & & $(0.03)$ \\
\hline \multirow[t]{2}{*}{ Size } & $0.41 * * *$ & $0.25 * * *$ & $0.30 * * *$ & $0.37 * * *$ \\
\hline & $(0.03)$ & $(0.03)$ & $(0.03)$ & $(0.03)$ \\
\hline \multirow[t]{2}{*}{ Online } & -0.20 & -0.24 & -0.05 & -0.20 \\
\hline & $(0.14)$ & $(0.25)$ & $(0.04)$ & $(0.14)$ \\
\hline Constant & $\begin{array}{c}12.44 * * * \\
(0.45)\end{array}$ & $\begin{array}{c}14.59 * * * \\
(0.43)\end{array}$ & $\begin{array}{c}13.93 * * * \\
(0.41)\end{array}$ & $\begin{array}{c}12.60 * * * \\
(0.42)\end{array}$ \\
\hline Firm Fixed Effects & Yes & Yes & Yes & Yes \\
\hline Category Fixed Effects & Yes & Yes & Yes & Yes \\
\hline $\mathrm{N}$ & 3,500 & 2,500 & 2,500 & 3,500 \\
\hline R-squared & 0.34 & 0.21 & 0.30 & 0.40 \\
\hline Number of unique firms & 832 & 712 & 708 & 832 \\
\hline
\end{tabular}

Notes: This table presents regression results for model (2) using the full sample for 2006-2012. Data for transaction and interaction capabilities are only available for 2007-2011, which reduces the sample size to 2,500 for those capabilities. Outcome is measured with $\ln ($ Sales $)$. Capability is a vector of firm-time varying functionalities within the e-commerce capability [39] that a firm reports having, and zero otherwise. Size is measured as $\ln$ (Total monthly visits). Online is an indicator variable equal to one if the firm only sells online only, and zero for click-and-mortar firms. Each regression includes firm and merchandise category fixed effects. $* * *, * *, *$ represent significance at the p-value $<0.01,0.05$, and 0.10 , respectively, based on two-tailed tests. Robust standard errors are reported in brackets. We define each individual e-commerce functionality in Appendix A. 


\section{Table 6. The Impact of E-commerce Capabilities on Unique Monthly Visitors}

\begin{tabular}{|c|c|c|c|c|}
\hline VARIABLES & $(1)$ & $(2)$ & (3) & (4) \\
\hline \multicolumn{5}{|l|}{ Information Capability } \\
\hline \multirow[t]{2}{*}{ Product comparisons } & -0.00 & & & \\
\hline & $(0.05)$ & & & \\
\hline \multirow[t]{2}{*}{ Syndicated content } & 0.05 & & & \\
\hline & $(0.04)$ & & & \\
\hline \multicolumn{5}{|l|}{ Transaction Capability } \\
\hline \multirow[t]{2}{*}{ Catalog quick order } & & $-0.08^{*}$ & & \\
\hline & & $(0.05)$ & & \\
\hline \multirow[t]{2}{*}{ Deferred payment } & & $-0.16^{* * *}$ & & \\
\hline & & $(0.06)$ & & \\
\hline \multirow[t]{2}{*}{ PayPal express checkout } & & -0.00 & & \\
\hline & & $(0.07)$ & & \\
\hline \multicolumn{5}{|l|}{ Interaction Capability } \\
\hline Frequent buyer program & & & $\begin{array}{c}0.02 \\
(0.05)\end{array}$ & \\
\hline Personalization & & & $\begin{array}{l}-0.06 \\
(0.04)\end{array}$ & \\
\hline \multicolumn{5}{|l|}{ Infrastructure Capability } \\
\hline \multirow[t]{2}{*}{ Content delivery } & & & & $0.10 *$ \\
\hline & & & & $(0.06)$ \\
\hline \multirow[t]{2}{*}{$C R M$} & & & & $-0.20 * * *$ \\
\hline & & & & $(0.04)$ \\
\hline \multirow[t]{2}{*}{ E-commerce platform } & & & & -0.01 \\
\hline & & & & $(0.05)$ \\
\hline \multirow[t]{2}{*}{ Web performance monitor } & & & & 0.03 \\
\hline & & & & $(0.04)$ \\
\hline \multirow[t]{2}{*}{ Size } & $0.55 * * *$ & $0.40 * * *$ & $0.69 * * *$ & $0.59 * * *$ \\
\hline & $(0.04)$ & $(0.06)$ & $(0.05)$ & $(0.04)$ \\
\hline \multirow[t]{2}{*}{ Online } & 0.07 & 0.04 & -0.10 & 0.10 \\
\hline & $(0.18)$ & $(0.19)$ & $(0.11)$ & $(0.18)$ \\
\hline Constant & $\begin{array}{c}3.48 * * * \\
(0.72)\end{array}$ & $\begin{array}{c}6.09 * * * \\
(1.12)\end{array}$ & $\begin{array}{c}0.95 \\
(1.01)\end{array}$ & $\begin{array}{c}2.90 * * * \\
(0.76)\end{array}$ \\
\hline Firm Fixed Effect & Yes & Yes & Yes & Yes \\
\hline Category Fixed Effect & Yes & Yes & Yes & Yes \\
\hline $\mathrm{N}$ & 3,489 & 2,492 & 2,495 & 3,489 \\
\hline R-squared & 0.13 & 0.05 & 0.11 & 0.14 \\
\hline Number of unique firms & 831 & 711 & 708 & 831 \\
\hline
\end{tabular}

Notes: This table presents regression results for model (2) using the full sample for 2006-2012. Data for transaction and interaction capabilities are only available for 2007-2011, which reduces the sample size to 2,500 for those capabilities. Outcome is measured with $\ln$ (Unique monthly visitors). Capability is vector of firm-time varying functionalities within the e-commerce capability [39] that a firm reports having, and zero otherwise. Size is measured as $\ln ($ Sales $)$. Online is an indicator variable equal to one if the firm only sells online only, and zero for click-and-mortar firms. Each regression includes firm and merchandise category fixed effects. ***, **, * represent significance at the p-value $<0.01,0.05$, and 0.10 , respectively, based on two-tailed tests. Robust standard errors are reported in brackets. We define each individual e-commerce functionality in Appendix A. 


\begin{tabular}{|c|c|c|c|c|}
\hline VARIABLES & (1) & (2) & (3) & (4) \\
\hline \multicolumn{5}{|l|}{ Information Capability } \\
\hline \multirow[t]{2}{*}{ Product comparisons } & 0.04 & & & \\
\hline & $(0.03)$ & & & \\
\hline \multirow[t]{2}{*}{ Syndicated content } & $0.09 * *$ & & & \\
\hline & $(0.03)$ & & & \\
\hline \multicolumn{5}{|l|}{ Transaction Capability } \\
\hline \multirow[t]{2}{*}{ Catalog quick order } & & 0.01 & & \\
\hline & & $\begin{array}{l}(0.05) \\
-0.01\end{array}$ & & \\
\hline Deferred payment & & $(0.04)$ & & \\
\hline PayPal express checkout & & $\begin{array}{c}0.02 \\
(0.04)\end{array}$ & & \\
\hline \multicolumn{5}{|l|}{ Interaction Capability } \\
\hline Frequent buyer program & & & $\begin{array}{c}0.09 * * \\
(0.04)\end{array}$ & \\
\hline Personalization & & & $\begin{array}{c}-0.05^{*} \\
(0.03)\end{array}$ & \\
\hline \multicolumn{5}{|l|}{ Infrastructure Capability } \\
\hline Content delivery & & & & $\begin{array}{l}0.08^{*} \\
(0.04)\end{array}$ \\
\hline$C R M$ & & & & $\begin{array}{l}-0.05 \\
(0.03)\end{array}$ \\
\hline E-commerce platform & & & & 0.01 \\
\hline Web performance monitor & & & & $\begin{array}{l}(0.05) \\
0.07 * *\end{array}$ \\
\hline Size & $0.69^{* * *}$ & $0.57 * * *$ & $0.69^{* * *}$ & $\begin{array}{c}(0.03) \\
0.68^{* * * *}\end{array}$ \\
\hline \multirow[t]{2}{*}{ Online } & $\begin{array}{c}(0.03) \\
0.18\end{array}$ & $\begin{array}{c}(0.05) \\
0.26\end{array}$ & $\begin{array}{l}(0.04) \\
-0.12\end{array}$ & $\begin{array}{c}(0.04) \\
0.19\end{array}$ \\
\hline & $(0.14)$ & $(0.17)$ & $(0.09)$ & $(0.14)$ \\
\hline Constant & $\begin{array}{c}1.62 * * * * \\
(0.62)\end{array}$ & $\begin{array}{c}3.57 * * * \\
(0.92)\end{array}$ & $\begin{array}{c}1.74 * * \\
(0.83)\end{array}$ & $\begin{array}{c}1.62 * * \\
(0.67)\end{array}$ \\
\hline Firm Fixed Effect & Yes & Yes & Yes & Yes \\
\hline Category Fixed Effect & Yes & Yes & Yes & Yes \\
\hline $\mathrm{N}$ & 3,500 & 2,500 & 2,500 & 3,500 \\
\hline R-squared & 0.31 & 0.16 & 0.22 & 0.31 \\
\hline Number of unique firms & 832 & 712 & 708 & 832 \\
\hline
\end{tabular}

Notes: This table presents regression results for model (2) using the full sample for 2006-2012. Data for transaction and interaction capabilities are only available for 2007-2011, which reduces the sample size to 2,500 for those capabilities. An Outcome is measured with $\ln$ (Total monthly visitors). Capability is a vector of firmtime varying functionalities within the e-commerce capability [39] that a firm reports having, and zero otherwise. Size is measured as $\ln$ (Sales). Online is an indicator variable equal to one if the firm only sells online only, and zero for click and mortar firms. Each regression includes firm and merchandise category fixed effects. $* * *, * *, *$ represent significance at the p-value $<0.01,0.05$, and 0.10 , respectively, based on two-tailed tests. Robust standard errors are reported in brackets. We define each individual e-commerce functionality in Appendix A. 


\subsection{Results for Early and Late Adopters on Online Retailer Performance}

We next hypothesize in $\mathrm{H} 2$ that firms that are early adopters of a capability will see a larger positive impact on online retailer performance compared with firms that adopt the capability later in time. To evaluate the adoption of e-commerce capabilities, the associated ecommerce functionalities are employed as indicators of adoption [3]. To test this hypothesis, regression model (1) is used and coefficients for adopters of the functionality are compared before diffusion to coefficients for late adopters of the same functionality after diffusion. We test each functionality separately because intend to observe the timing of adoption which occurs at different points in time for each functionality, even within an e-commerce capability. ${ }^{13}$ Therefore, a strength of this specification is that the different subsamples allow early adopters to be excluded from the late adopter regression, and vice versa. The early adopter sample excludes companies that adopt the functionality in the future (after diffusion), making the control group nonadopters. Likewise, the late adopter sample excludes early adopters (pre diffusion), making the control group nonadopters.

We create three subsamples - an early adopter subsample, a late adopter subsample, and a nonadopter subsample - while retaining the entire period keeping $t$ unchanged). In this context, an early adopter firm adopts the e-commerce functionality prior to the diffusion threshold being examined, which varies by functionality (see Table 2). First, we identify firms that are early adopters of specific e-commerce functionality, and we drop future (i.e., late) adopters of the functionality. Specifically, the variable EcomFunctionality takes a value equal to one when the firm adopts the e-commerce functionality before diffusion (i.e., early adopter) and a value equal to zero for any nonadopting firm. For example, the e-commerce functionality

\footnotetext{
${ }^{13}$ We run separate regressions for personalization because we observe two phases of diffusion during our study.
} 
product comparisons diffused from the early adopter phase to the early majority phase in 2007. Thus, in this subsample, an early adopter is a firm that has adopted product comparisons functionality in 2006 (or prior to data collection). Catalog quick order diffused from early majority to late majority in 2012. Thus, an early adopter is identified as a firm that adopts catalog quick order in 2006-2011.

Next, we identify firms that adopted the e-commerce functionality in the period (s) after diffusion has taken place (i.e., late adopters), and we drop the early adopters. Specifically, the variable EcomFunctionality takes a value equal to one in the year(s) the firm has adopted the capability after diffusion (e.g., late adopter), and a value equal to zero for nonadopting firms. For example, because early adopters of product comparisons adopted in 2006 or earlier, late adopters in this subsample of firms adopted product comparisons in 2007-2012. In addition, because early adopters of catalog quick order adopted in 2006-2011, late adopters of catalog quick order are firms that adopted this functionality in 2012. We run separate regressions for personalization because we observe two phases of diffusion during our study.

We present results for $\mathrm{H} 2$ in Table 8. We include all control variables from regression model (1) but only present the coefficient of interest, EcomFunctionality, in the table for brevity. We show the full regression results in an online appendix. We report results for our dependent variables sales (columns (1)-(3)), unique monthly visitors (columns (4)-(6)), and total monthly visitors (columns (7)-(9)). To find support for H2, we would expect early adopters to have an incremental benefit over late adopters, and therefore, we would expect a larger positive coefficient for EcomFunctionality in the early adopter subsample compared with the same coefficient in the late adopter subsample. We test the difference in coefficients for the early 
adopters and late adopters for sales, unique monthly visitors, and total monthly visitors in columns (3), (6), and (9), respectively.

In Table 8 , when we use $\ln ($ Sales $)$ as our dependent variable, we find a positive and significant coefficient for all but one e-commerce functionality (PayPal express checkout) when the firm is an early adopter of the functionality (column (1)). For late adopting firms (column (2)), coefficients are generally smaller, and in a couple of cases, coefficients are negative. In addition, we find a significant difference in the coefficients for the two subsamples for product comparisons, syndicated content, frequent buyer programs, and e-commerce platforms. In two cases with infrastructure-related functionality, content delivery and web performance monitor, we find larger, positive coefficients for the late adopter subsample, indicating higher sales for late adopters; however, we do not find a significant difference in coefficients. Overall, we find support for $\mathrm{H} 2$ that early adoption of a functionality is associated with greater incremental sales.

In Table 8, columns (4)-(6), when we use (Unique monthly visitors) as our dependent variable, coefficients for two functionalities, CRM and web performance monitor, are positive and are statistically significant in the early adopter subsample. Furthermore, mixed results are found for the late adopter subsample. For CRM, the coefficient is positive in both subsamples but only statistically significant in the early adopter subsample (although the magnitudes are both very small). The tests of differences in coefficients for CRM provide support for $\mathrm{H} 2$.

The results generally do not support an early adopter benefit for (Total monthly visitors) (columns (7)-(9)). In general, coefficients for EcomFunctionality are not statistically different from zero for either subsample. The one exception is an infrastructure-related functionality, web performance monitoring, for which we find a positive and statistically significant coefficient in the early adopter subsample and an insignificant coefficient in the late adopter subsample. 
Further, we find a marginal statistical difference in the two coefficients (p-value $<0.1)$ that provides support for $\mathrm{H} 2$. 
Table 8. The Impact of Adoption E-commerce Capabilities in the Early Phase vs. Late Phase of Diffusion

\begin{tabular}{|c|c|c|c|c|c|c|c|c|c|c|c|c|c|c|c|}
\hline & & $\begin{array}{c}(1) \\
\text { Early } \\
\text { Adopter }\end{array}$ & & $\begin{array}{c}(2) \\
\text { Late } \\
\text { Adopter }\end{array}$ & (3) & & $\begin{array}{c}\text { (4) } \\
\text { Early } \\
\text { Adopter }\end{array}$ & & $\begin{array}{c}(5) \\
\text { Late } \\
\text { Adopter }\end{array}$ & (6) & & $\begin{array}{c}(7) \\
\text { Early } \\
\text { Adopters }\end{array}$ & & $\begin{array}{c}(8) \\
\text { Late } \\
\text { Adopters }\end{array}$ & (9) \\
\hline Dependent variable $=$ & $\mathrm{N}$ & Sales & $\mathrm{N}$ & Sales & $\begin{array}{c}\text { Diff } \\
\text { in } \\
\text { Coeff }\end{array}$ & $\mathrm{N}$ & $\begin{array}{l}\text { Unique } \\
\text { Monthly } \\
\text { Visitors }\end{array}$ & $\mathrm{N}$ & $\begin{array}{l}\text { Unique } \\
\text { Monthly } \\
\text { Visitors }\end{array}$ & $\begin{array}{l}\text { Diff in } \\
\text { Coeff }\end{array}$ & $\mathrm{N}$ & $\begin{array}{c}\text { Total } \\
\text { Monthly } \\
\text { Visits }\end{array}$ & $\mathrm{N}$ & $\begin{array}{c}\text { Total } \\
\text { Monthly } \\
\text { Visits }\end{array}$ & $\begin{array}{c}\text { Diff } \\
\text { in } \\
\text { Coeff }\end{array}$ \\
\hline \multicolumn{16}{|l|}{ Information Capability } \\
\hline Product comparisons & 396 & $0.98 * * *$ & 2,743 & $0.11 * * *$ & $* * *$ & 394 & $-0.32 * * *$ & 2,735 & 0.01 & \multirow[t]{3}{*}{$* * *$} & 396 & $-0.23 *$ & 2,743 & 0.06 & \\
\hline Syndicated content & 412 & $0.66^{* * *}$ & 2,655 & 0.06 & $* * *$ & 410 & 0.13 & 2,647 & $0.11 * *$ & & 412 & 0.12 & 2,655 & $0.10 * *$ & \\
\hline \multicolumn{15}{|l|}{ Transaction Capability } & \\
\hline Catalog quick order & 1,680 & $0.21 * * *$ & 319 & -0.31 & & 1,673 & -0.04 & 319 & 0.42 & & 1,680 & -0.02 & 319 & 0.43 & \\
\hline Deferred payment & 435 & $0.57 * * *$ & 2,302 & $-0.15 * * *$ & & 432 & $-0.29 *$ & 2,297 & $-0.15^{* *}$ & & 435 & $-0.39 * * *$ & 2,302 & -0.05 & \\
\hline $\begin{array}{l}\text { PayPal express } \\
\text { checkout }\end{array}$ & 430 & 0.00 & 2,700 & $0.04 *$ & & 427 & -0.09 & 2,692 & $-0.11 *$ & & 430 & -0.10 & 2,700 & -0.03 & \\
\hline \multicolumn{16}{|l|}{ Interaction Capability } \\
\hline Frequent buyer program & 384 & $0.64 * * *$ & 2,605 & $0.10 * * *$ & \multirow[t]{4}{*}{$* * *$} & 382 & 0.06 & 2,598 & 0.00 & \multirow[b]{2}{*}{ * } & 384 & 0.13 & 2,605 & $0.07 *$ & \\
\hline Personalization:EA-EM & 332 & $0.23 * *$ & 1,282 & $0.18^{* * *}$ & & 370 & 0.15 & 1,277 & -0.05 & & 370 & 0.00 & 1,282 & -0.02 & \\
\hline Personalization:EM-LM & 1,363 & $0.18 * * *$ & 291 & 0.08 & & 1,358 & -0.06 & 291 & 0.02 & $* * *$ & 1,363 & -0.03 & 291 & -0.02 & \\
\hline \multicolumn{15}{|l|}{ Infrastructure Capability } & \\
\hline Content delivery & 807 & $0.13^{* * *}$ & 1,557 & $0.20 * * *$ & \multirow{4}{*}{$* * *$} & 802 & 0.03 & 1,553 & $0.20 * *$ & \multirow{4}{*}{$\begin{array}{c}* * * \\
*\end{array}$} & 807 & 0.08 & 1,557 & 0.02 & \\
\hline$C R M$ & 1,142 & $0.19 * * *$ & 859 & -0.19 & & 1,137 & $0.08 *$ & 855 & 0.20 & & 1,142 & 0.06 & 859 & 0.24 & \multirow{3}{*}{$\begin{array}{l}* * \\
*\end{array}$} \\
\hline E-commerce platform & 412 & $0.44 * * *$ & 1,277 & 0.08 & & 409 & -0.23 & 1,272 & 0.00 & & 412 & -0.13 & 1,277 & $0.10^{*}$ & \\
\hline $\begin{array}{l}\text { Web performance } \\
\text { monitor }\end{array}$ & 1,887 & $0.12 * * *$ & 454 & $0.18 * * *$ & & 1,881 & $0.10 * *$ & 452 & 0.11 & & 1,887 & $0.18^{* * *}$ & 454 & -0.02 & \\
\hline
\end{tabular}

This table presents regression results for model (1). The model includes all control variables and fixed effects for firm (for all regressions with more than one year) and merchant category, but we only present coefficients for EcomFunctionality for brevity. Outcome is measured with three dependent variables: $\ln ($ Sales) in columns (1)-(3), $\ln ($ Unique

monthly visitors) in columns (4)-(6), and $\ln ($ Total monthly visitors) in columns (7)-(9). Columns (1), (4), and (7) present results for the early adopter subsample, and columns (2), (5), and (8) present results for the late adopter subsample. For the columns titled Early Adopter, EcomFunctionality takes on a value equal to one when the firm adopts the capability prior to diffusion and zero for nonadopting firms. Late (i.e., future) adopters of the functionality are dropped from this subsample. For the columns titled Late Adopter, EcomFunctionality takes on a value equal to one when the firm adopts the functionality after diffusion takes place, and zero for nonadopting firms. Early adopters are dropped from this subsample Refer to the text (Section 5.4) for more detail about construction of these subsamples. Columns (3), (6), and (9) report differences in coefficients for the two subsamples. Size is measured as $\ln$ (Sales) except when Sales is the dependent variable, and then we control for size using total monthly visits. Online is an indicator variable equal to one if the firm only sells online only, and zero otherwise. Each regression includes firm and merchandise category fixed effects. ***,**,* represent significance at the p-value $<$ $0.01,0.05$, and 0.10 , respectively, based on two-tailed tests. Robust standard errors are not reported for brevity. We define each individual e-commerce functionality in Appendix A. 


\subsection{Results for the Impact of Diffusion on Online Retailer Performance}

In H3a, we hypothesize that the positive effect of information, transaction, and ecommerce capabilities on an online retailer's performance will diminish over time. To test this hypothesis, we use the coefficients determined from $\mathrm{H} 2$ (copied from Table 8 above) and run the third regression using model (1). Notably, for $\mathrm{H} 2$, the impact of the e-commerce functionalities is examined for early adopters before diffusion occurs. Now, in H3, we also examine the impact of the e-commerce functionalities on early adopters after diffusion occurs. We copy the coefficients from $\mathrm{H} 2$ (Table 8) and generate a third set of coefficients for comparison purposes. In this third regression, we use our definition for the early adopter, but rather than testing for the entire period, we limit the regression to the later periods after diffusion has occurred. We refer to this subsample as early adopter-late. We refer to the three sets of coefficients as early adopterearly (from H2), late adopter-late (from H2), and early adopter-late (from H3). Similar to H2, because adoption and diffusion take place at different points in time for each e-commerce functionality, the number of observations in each regression will vary for each functionality based on the data availability previously discussed (see section 4.1).

To find support for H3, we should observe a smaller coefficient for EcomFunctionality for early adopter-late compared with the coefficient for early adopter-early because the early adopter benefit diminishes over time. In addition, the coefficient for EcomFunctionality should be higher for late adopter-late compared with early adopter-late. This second result supports the idea that the late adopters are seeing a boost in performance compared with early adopters experiencing diminished benefits in the same period.

Table 9 tabulates the results for H3a. We reproduce the coefficients for EcomFunctionality for the early adopter-early regression (from Table 8) in columns (1) and (6), 
and late adopter-late regression (from Table 8) in columns (3) and (8), respectively. We present coefficients for EcomFunctionality for the early adopter-late regression in columns (2) and (7). We present the test for the difference in coefficients for the three subsamples in columns (4), (5), (9), and (10). We run the full regression model with the control variables and fixed effects but present only the coefficients for EcomFunctionality for brevity. The full regression results are available in an online appendix. We show results for sales and unique monthly visitors in Panel A and total monthly visitors in Panel B.

When we use $\ln ($ Sales $)$ as the dependent variable, regression results show that coefficients are generally smaller for the early adopters in the late period (column (2)) compared with the same subsample of early adopters in the early period (column (1)), suggesting that early adopters of the e-commerce functionality had lower sales in the later period. In addition, the coefficients are found statistically different for every functionality except two, catalog quick order and content delivery (column (4). We also note that for late adopters, having the functionality is associated with higher sales for firms that have four functionalities (column (3)). Specifically, sales are positive for late adopters of product comparisons, PayPal express, content delivery, and web performance monitor, and coefficients for late adopters in the late period are generally larger (and statistically different) than the coefficients for the early adopters in the late period for these functionalities. Overall, we find strong support for $\mathrm{H} 3 \mathrm{a}$, strengthening the notion that the impact of early adoption dissipates over time. Thus, late adopters experience a significantly larger benefit in the later phases of adoption relative to early adopters that experience diminished benefits of adoption over time.

We find mixed results for $\mathrm{H} 3 \mathrm{a}$ when we use (Unique monthly visitors) as the dependent variable. This outcome is partially driven by the results for the early adopter subsample in the 
early period showing a negative relation with unique monthly visitors in the early period. For CRM and web performance monitor, the performance impact dissipates over time for the early adopters as the positive and statistically significant coefficient in the early period turns negative for CRM and insignificant for web performance monitor in the late period. These results provide some support for H3a. However, a comparison of the late adopters with the early adopters in the late period reveals that negative coefficients become statistically insignificant for the late adopters. This is true for catalog quick order, CRM, and web performance monitor, and we find a statistically significant difference in coefficients for these three functionalities (column (10). Thus, there is some support for our hypothesis H3a that late adopters have a statistically significant difference in unique monthly visitors relative to early adopters' performance in the late period.

We find limited support for our hypothesis when we use (Total monthly visitors) as the dependent variable (Table 9, Panel B). When we compare coefficients for the early adopter in the early period and early adopter in the late period, we find evidence of a diminishing impact only for web performance monitor. This is the only case in which the coefficient is positive and statistically significant for the early adopters in the early period and statistically insignificant for this subsample in the late period. This hypothesis is supported with a test of difference in coefficients, which is statistically significant. 
Table 9 Panel A. Examination of Whether the Performance Benefits of the Adoption of E-Commerce Capabilities Persist After Diffusion

\begin{tabular}{|c|c|c|c|c|c|c|c|c|c|c|}
\hline \multirow[t]{2}{*}{ Dependent Variable = } & \multicolumn{5}{|c|}{ Sales } & \multicolumn{5}{|c|}{ Unique Monthly Visitors } \\
\hline & $\begin{array}{c}\text { (1) } \\
\text { Early } \\
\text { Adopter } \\
\text {-Early }\end{array}$ & $\begin{array}{c}\text { (2) } \\
\text { Early } \\
\text { Adopter } \\
\text {-Late }\end{array}$ & $\begin{array}{c}(3) \\
\text { Late } \\
\text { Adopter } \\
\text {-Late }\end{array}$ & $\begin{array}{c}\text { (4) } \\
\text { Diff in } \\
\text { Coeff. } \\
(1)-(2)\end{array}$ & $\begin{array}{c}(5) \\
\text { Diff in } \\
\text { Coeff. } \\
(3)-(2)\end{array}$ & $\begin{array}{c}\text { (6) } \\
\text { Early } \\
\text { Adopter } \\
\text {-Early }\end{array}$ & $\begin{array}{c}\text { (7) } \\
\text { Early } \\
\text { Adopter } \\
\text {-Late }\end{array}$ & $\begin{array}{c}(8) \\
\text { Late } \\
\text { Adopter } \\
\text {-Late }\end{array}$ & $\begin{array}{c}(9) \\
\text { Diff in } \\
\text { Coeff. } \\
(6)-(7)\end{array}$ & $\begin{array}{c}(10) \\
\text { Diff in } \\
\text { Coeff. } \\
(8)-(7)\end{array}$ \\
\hline \multicolumn{11}{|l|}{ Information Capability } \\
\hline $\begin{array}{l}\text { Product comparisons } \\
\text { Syndicated content }\end{array}$ & $\begin{array}{l}0.98 * * * \\
0.66 * * *\end{array}$ & $\begin{array}{l}-0.05 \\
-0.15^{*}\end{array}$ & $\begin{array}{l}0.11 * * * \\
0.06\end{array}$ & $\begin{array}{l}* * * \\
* * *\end{array}$ & $\begin{array}{l}* * * \\
* *\end{array}$ & $\begin{array}{l}-0.32 * * * \\
0.13\end{array}$ & $\begin{array}{l}0.07 \\
-0.04\end{array}$ & $\begin{array}{l}0.01 \\
0.11 * *\end{array}$ & $* * *$ & \\
\hline \multicolumn{11}{|l|}{ Transaction Capability } \\
\hline $\begin{array}{l}\text { Catalog quick order } \\
\text { Deferred payment }\end{array}$ & $\begin{array}{l}0.21 * * * \\
0.57 * * *\end{array}$ & $\begin{array}{l}-0.16 \\
-0.23 * * *\end{array}$ & $\begin{array}{l}-0.31 \\
-0.15 * * *\end{array}$ & $* * *$ & & $\begin{array}{l}-0.04 \\
-0.29 *\end{array}$ & $\begin{array}{l}-0.62 * * \\
-0.04\end{array}$ & $\begin{array}{l}0.42 \\
-0.15 * *\end{array}$ & $*$ & $* * *$ \\
\hline $\begin{array}{l}\text { PayPal express checkout } \\
\text { Infrastructure Capabili }\end{array}$ & 0.00 & $-0.30 * * *$ & $0.04 *$ & \multicolumn{3}{|c|}{ Infrastructure Capability } & 0.02 & $-0.11 *$ & & \\
\hline Content delivery & $0.13 * * *$ & $0.55 * * *$ & $0.20 * * *$ & & & 0.03 & -0.02 & $0.20 * *$ & & \\
\hline$C R M$ & $0.19 * * *$ & $-0.29 * * *$ & -0.19 & $* *$ & $* * *$ & $0.08 *$ & $-0.75 * * *$ & 0.20 & $* * *$ & $* *$ \\
\hline $\begin{array}{l}\text { E-commerce } \\
\text { platform }\end{array}$ & $0.44 * * *$ & 0.02 & 0.08 & $* * *$ & & -0.23 & 0.01 & 0.00 & $*$ & \\
\hline $\begin{array}{l}\text { Web performance } \\
\text { monitor }\end{array}$ & $0.12 * * *$ & $-0.11 * * *$ & $0.18 * * *$ & $* * *$ & $* * *$ & $0.10 * *$ & -0.23 & 0.11 & $* *$ & $* *$ \\
\hline
\end{tabular}


Table 9 Panel B. Examination of Whether the Performance Benefits of the Adoption of E-Commerce Capabilities Persist After Diffusion

\begin{tabular}{|c|c|c|c|c|c|}
\hline \multirow[t]{2}{*}{ Dependent Variable = } & \multicolumn{5}{|c|}{ Total Monthly Visitors } \\
\hline & $\begin{array}{c}\text { (1) } \\
\text { Early } \\
\text { Adopter } \\
\text {-Early }\end{array}$ & $\begin{array}{c}\text { (2) } \\
\text { Early } \\
\text { Adopter } \\
\text {-Late }\end{array}$ & $\begin{array}{c}(3) \\
\text { Late } \\
\text { Adopter } \\
\text {-Late }\end{array}$ & $\begin{array}{c}(4) \\
\text { Diff in } \\
\text { Coeff. } \\
(1)-(2)\end{array}$ & $\begin{array}{c}(5) \\
\text { Diff in } \\
\text { Coeff. } \\
(3)-(2)\end{array}$ \\
\hline \multicolumn{6}{|l|}{ Information Capability } \\
\hline Product comparisons & $-0.23 *$ & -0.03 & 0.06 & $*$ & \\
\hline Syndicated content & 0.12 & 0.06 & $0.10 * *$ & & \\
\hline \multicolumn{6}{|l|}{ Transaction Capability } \\
\hline Catalog quick order & -0.02 & -0.18 & 0.43 & & $*$ \\
\hline Deferred payment & $-0.39 * * *$ & -0.03 & -0.05 & $* *$ & \\
\hline PayPal express checkout & -0.10 & -0.04 & -0.03 & & \\
\hline \multicolumn{6}{|l|}{ Infrastructure Capability } \\
\hline Content delivery & 0.08 & -0.01 & 0.02 & & \\
\hline$C R M$ & 0.06 & $0.21 * * *$ & 0.24 & $*$ & \\
\hline E-commerce platform & -0.13 & -0.13 & $0.10 *$ & & \\
\hline $\begin{array}{l}\text { Web performance } \\
\text { monitor }\end{array}$ & $0.18 * * *$ & 0.02 & -0.02 & $* * *$ & $*$ \\
\hline
\end{tabular}

This table presents regression results for model (1), for functionalities in the information, transaction, and infrastructure capability. The model includes all control variables and fixed effects for firm (for all regressions with more than one year) and merchant category, but we only present coefficients for EcomFunctionality for brevity. Outcome is measured with three dependent variables. Panel A shows results for $\ln ($ Sales) and $\ln ($ Unique monthly visitors), and Panel B shows results for $\ln ($ Total monthly visitors). Columns (1) and (6) present results for EcomFunctionality for early adopter-early, columns (2) and (7) present results for the early adopter-late, and columns (3) and (8) present results for late adopterlate. For early adopter-early, EcomFunctionality takes a value equal to one when the firm adopts the functionality prior to diffusion, and zero for nonadopting firms; future adopters of the functionality are dropped. For early adopter-late, we use the early adopter-early subsamples but examine only for the post-diffusion time periods. For late adopterlate, EcomFunctionality takes a value equal to one when the firm adopts the functionality after diffusion takes place, and zero for nonadopting firms; early adopters are dropped from this regression. Refer to the text (Section 5.4) for more detail about construction of these subsamples. Columns (4), (5), (9), and (10) report the statistical difference between the subsamples using a test of differences in coefficients. Size is measured as $\ln ($ Sales) except when sales is the dependent variable, and then we control for size using total monthly visits. Online is an indicator variable equal to one if the firm only sells online only, and zero otherwise. Each regression includes firm (for all regressions with more than one year) and merchandise category fixed effects. ***,**,* represent significance at the p-value $<0.01,0.05$, and 0.10 , respectively, based on two-tailed tests. Robust standard errors are not reported for brevity. We define each individual e-commerce functionality in Appendix A. 
Consequently, we move to $\mathrm{H} 3 \mathrm{~b}$, our last hypothesis. It predicts that the positive effect of interaction capabilities on an online retailer's performance will persist over time. We use model (1) and the two early adopter subsamples previously described. We compare the early adopter subsample (early) before diffusion to the early adopter subsample (late) after diffusion. A test of difference is performed in coefficients and no statistical difference is expected in the coefficient for EcomFunctionality in the early period compared with the coefficient for EcomFunctionality in the late period. We present the results for interaction-related functionalities in Table 10, presenting only the coefficient for EcomFunctionality. We present full regression results in an online appendix. We report statistical significance for the test of differences in coefficients in columns (3) and (6).

We document that the impact of adopting personalization on sales persists over time (for both diffusion phases). The coefficients for EcomFunctionality are positive and statistically significant for both subsamples and the tests of differences in coefficients show that the coefficients are not different from each other. In general, we find that interaction functionalities have no impact on monthly or unique visitors. Except for personalization (diffusing to early majority phase), the coefficients are not statistically different from zero and this persists after diffusion, thus supporting H3b. From an institutional standpoint, the results generally indicate that the benefits of personalization e-commerce functionalities on sales persist over time. 
Table 10. Examination of Whether the Performance Benefits of the Adoption of Interaction Capabilities Persist After Diffusion

\begin{tabular}{|c|c|c|c|c|c|c|c|c|c|}
\hline \multirow[t]{2}{*}{ Dependent Variable $=$} & \multicolumn{3}{|c|}{ Sales } & \multicolumn{3}{|c|}{ Unique Monthly Visitors } & \multicolumn{3}{|c|}{ Total Monthly Visitors } \\
\hline & (1) & (2) & $(3)$ & (4) & (5) & (6) & (7) & $(8)$ & (9) \\
\hline & Early & Early & Diff in & Early & Early & Diff in & Early & Early & Diff in \\
\hline & Adopter & Adopter & Coeff. & Adopter & Adopter & Coeff. & Adopter & Adopter & Coeff. \\
\hline & -Early & -Late & $(1)-(2)$ & -Early & -Late & $(4)-(5)$ & -Early & -Late & $(7)-(8)$ \\
\hline \multicolumn{10}{|l|}{ Interaction Capability } \\
\hline Frequent buyer program & $0.64 * * *$ & $-0.35 * *$ & $* * *$ & 0.06 & 0.10 & & 0.13 & 0.05 & \\
\hline Personalization_EM & $0.23 * *$ & $0.36 * *$ & & 0.15 & $0.39 * * *$ & $* * *$ & 0.00 & 0.14 & \\
\hline Personalization_LM & $0.18 * * *$ & $0.20 * *$ & & -0.06 & 0.03 & & -0.03 & 0.02 & \\
\hline
\end{tabular}

This table presents regression results for model (1), for functionalities in the information, transaction, and infrastructure capability. The model includes all control variables and fixed effects for the firm and merchant category, but we only present coefficients for EcomFunctionality for brevity. Outcome is measured with three dependent variables. Panel A shows results for $\ln$ (Sales) and $\ln$ (Unique monthly visitors), and Panel B shows results for $\ln$ (Total monthly visitors). Columns (1) and (6) present results for EcomFunctionality for early adopter-early, columns (2) and (7) present results for the early adopter-late, and columns (3) and (8) present results for late adopter-late. For early adopter-early, EcomFunctionality takes a value equal to one when the firm adopts the functionality prior to diffusion, and zero for nonadopting firms; future adopters of the functionality are dropped. For early adopter-late, we use the early adopter-early subsamples but examine only for the post-diffusion time periods. For late adopter-late, EcomFunctionality takes a value equal to one when the firm adopts the functionality after diffusion takes place, and zero for nonadopting firms; early adopters are dropped from this regression. Refer to the text (Section 5.4) for more detail about the construction of these subsamples. Columns (4), (5), (9), and (10) report the statistical difference between the subsamples using a test of differences in coefficients. Size is measured as $\ln ($ Sales) except when sales is the dependent variable, and then we control for size using total monthly visits. Online is an indicator variable equal to one if the firm only sells online only, and zero otherwise. Each regression includes firm and merchandise category fixed effects. ***,**** represent significance at the p-value $<0.01,0.05$, and 0.10, respectively, based on two-tailed tests. Robust standard errors are not reported for brevity. We define each individual e-commerce functionality in Appendix A. 


\section{Discussion and Conclusion}

The current research examines the relationship between online retailer adoption of ecommerce capabilities, reflected in e-commerce functionalities, and the business value they provide in terms of online retailer performance. It also assesses how the timing of adoption of different e-commerce capabilities (early versus late) may influence performance and the sustainability of performance benefit, even as additional online retailers adopt these same ecommerce capabilities over time. Based on an examination of e-commerce capabilities adoption activities by the top 500 internet retailers over seven years, we find that in general, adoption of ecommerce capabilities is positively associated with online sales and total monthly visitors. We also observe that for information, transaction, and infrastructure capabilities, the advantages of being an early adopter diminish over time as more firms adopt these capabilities. However, we find that some capabilities can generate sustainable performance. For example, in the case of interaction capabilities, performance advantages persist for personalization functionalities.

What does this mean for investment in e-commerce? First, it means the adoption of capabilities matters, especially for sales. Consistent with prior research and anecdotal evidence, we find a general benefit to sales through the adoption of capabilities, and some benefit for other performance outcomes depending on the capabilities adopted. Adoption of information and infrastructure capabilities benefits total monthly visitors, no benefit of any adoption on unique monthly visits were evident. Second, adopting early matters-sometimes. There is some benefit to being an early adopter, but not across the board for all e-commerce capabilities or all performance outcomes. Being an early adopter helps sales outcomes, whereby the influence of early mover advantage is associated with the adoption of information, interaction, and infrastructure capabilities. Only the earlier adoption of infrastructure was found to benefit 
outcomes related to unique and total monthly visitors. Third, adopting early can matter later, too. We note that information capabilities provide benefits for sales early on, but these benefits are not sustained over later phases of diffusion. However, firms wanting to adopt interaction and infrastructure capabilities may see greater advantage in terms of unique monthly visitors by waiting until later phases of adoption. Interaction capabilities may provide a sustainable benefit. For example, investment in personalization functionalities generated positive outcomes even through later phase changes. In summary, e-commerce capabilities are not uniform in their immediate and long-term effects on different metrics of performance. As such, they should be assessed in a disaggregated manner to distinguish each capability's specific contribution to ecommerce outcomes and to determine when those outcomes may be achieved after adoption.

Overall, this research contradicts the notion that adopting new digital capabilities will only provide early adopting firms with a fleeting competitive advantage. Our results show that this is true for some capabilities, but other capabilities offer early adopters lasting benefits, even after widespread capability adoption. For other capabilities, even later-adopting firms can register an increase in their performance metrics. We find that e-commerce capabilities can contribute to the creation of business value and that their influence on performance may be shortlived, delayed, or sustained.

\subsection{Implications for IS Research}

The current research has several implications for IS research at the intersection of the resource-based view and diffusion of innovation theory. This research contributes to e-commerce research by providing a more nuanced examination of e-commerce capabilities and their relationship to business value. We show that not all e-commerce capabilities contribute to business value equally, and those that contribute may do so only initially, later, or throughout their life cycle. By categorizing e-commerce capabilities by their contribution to business value, 
we can see differences in their contribution to performance. The same holds for e-commerce functionalities that underlie e-commerce capabilities. For example, functionalities associated with the information capability tend to generate a stronger initial performance benefit, while functionalities associated with the interaction capability tend to provide less initial benefit to the adopting online retailer but lead to stronger benefits later.

Although prior research has identified the performance advantages of investment in ecommerce capability [2], the variable effects of different e-commerce capabilities on the longterm competitive advantage remain largely overlooked. This research extends prior research by providing insight and explanation to those findings. For example, similar to Benitez et al. [56], we find that the positive effect of some e-commerce capabilities diminishes over time. Benitez et al. [56] focus mostly on functionalities associated with information and transaction capabilities, which we also find have diminishing benefits as competing firms adopt the technology. However, their analysis does not consider interaction capabilities, which we find may have a sustained positive impact on key performance metrics. Likewise, by disaggregating capabilities by business value creation, our research unpacks the unique nature of capability contribution, providing insight as to the relative importance of different capabilities to online retailers' performance over time. We observe that the adoption of certain capabilities may enable competitive advantage for some business activities and simultaneously limit advantages or yield disadvantages for other business activities [40]. By focusing on four value creation capabilities associated with the major processes and activities associated with the e-commerce life cycle, the current research contributes immensely to the understanding of how e-commerce capabilities can create sustainable business value. 
This research also contributes to the conceptualization of e-commerce capabilities in ecommerce research through its integration of the resource-based view with the diffusion of innovation theory. This has promising implications for research examining certain resource adoption issues such as EMA. The resource-based view generally proposes that capabilities can provide sustainable differential advantage only to the degree that the resources applied to them (in this research, as e-commerce functionalities) are valuable, rare, inimitable, and nonsubstitutable (or organized). Diffusion of innovation theory proposes that earlier adopters should be able to obtain a greater advantage over late adopters, which is particularly important in an innovation environment in which long-term competitive advantages may be limited. This research examines e-commerce capabilities and their contribution to value creation categories throughout a capability's life cycle. With this nuanced stance, our results extend prior research to show that certain types of e-commerce capabilities do provide an EMA, but that for certain capabilities, firms that are not at the forefront of innovation may benefit by waiting.

Furthermore, our findings provide additional insight similar to research that finds EMA for early adopters of certain informational and infrastructure e-commerce capabilities [18]. Like Wang et al. [18], we also find the existence of EMA, but we expand this research and find the EMA duration for e-commerce capabilities can differ due to the difference in the underlying value-creating activity being supported. For example, we find an enduring benefit for early adopters of interaction capabilities, such that adoption provides a sustainable benefit long after the capability has been adopted by competing online retailers. Therefore, the business value obtained from certain e-commerce capabilities may be more durable than commonly expected. Few recent studies highlight the link between e-commerce capabilities and the cultivation of customer relationships $[18,38]$. This suggests that the nature of interaction capabilities in 
supporting ongoing relationships with customers enables retailers that adopt such capabilities to see continued advantage across both financial and customer attraction performance metrics.

\subsection{Implications for Practice}

This study suggests that businesses must intentionally consider a comprehensive approach to e-commerce investment that encompasses not only performance expectations of capability adoption but also the timing of adoption. Understanding how adoption timing could impact performance measures helps organizations set realistic goals and expectations, while

efficiently allocating e-commerce operating budgets among competing projects. For instance, at a broad level, there is a clear sales advantage to adopting e-commerce capabilities. However, the effect of any e-commerce capability on sales is fleeting because none of the capabilities provide a sustained benefit. This suggests that firms will need to adopt e-commerce capabilities "early and often" to maintain a benefit on sales performance.

Beyond improvements in sales, we find that investments in infrastructure can provide a benefit to retailers that adopt later in the adoption cycle. This means that copying infrastructure capabilities, even after many online retailers have adopted, can still provide a significant benefit to the later adopter, suggesting there is a benefit for online retailers that "wait and see" before adopting infrastructure capabilities. Finally, certain interaction capabilities including personalization can provide sustainable benefits throughout the diffusion life cycle from early adopter to late majority. This outcome is likely due to the development of relationships with online customers resulting in improved and/or repeat sales. Implementation of interaction capabilities such as personalization makes sense earlier owing to the sustained value they generate over a longer period for the adopting retailer. Our findings suggest that online retailers 
may be able to maximize return on investment in some e-commerce capabilities by strategically timing adoption, depending on which performance measure is most important.

Taken together, we find no statistically significant difference in the number of visitors between adopters and nonadopters for most capabilities, although we find greater sales. This suggests that adopting online retailers' increased sales, driven by a similar number of unique and total visitors, is due more to the successful conversion of visitors to purchasers, perhaps through repeat sales. It is also possible that the increased sales performance is driven by larger purchase amounts per customer. We include a merchandise category fixed effect (e.g., computer/electronics versus flowers/gifts). Hence, the type of product sales may not drive the increased sales performance.

E-commerce capabilities may not provide an advantage for all performance measures in the same way and enhance operational efficiencies [56]. Thus, a firm must carefully evaluate what measures of performance best represent the business value expected by e-commerce capability investment. Appropriate testing and assessment are necessary to determine an appropriate approach to adopting e-commerce capabilities and their supporting functionalities.

\subsection{Limitations and Future Research}

This research has three key limitations that may influence its generalizability and require additional research. First, the data are collected annually by a third party for the purpose of describing the e-commerce capabilities, reflected by e-commerce functionalities, of the largest 500 online retailers. This research has no control over the manner of collection or the accuracy of the data. The analyses implicitly assume that e-commerce functionalities are available for the entire year of adoption, although it could be for less time. Similarly, the data are self-reported by the online retailers, and retailers may report functionalities in use or under development at the 
time of data collection. Other research has used this data successfully [21-23], and we use a large number of firm-year observations that should minimize data inconsistencies or errors. Future research should consider alternative data collection methods to validate results and to look at adoption behaviors at a more detailed level than by year.

Given the limited timeframe available for the data, we focus our examination on the functionalities and performance measures whereby e-commerce functionality adoption levels crossed established adoption phases identified in the diffusion of innovation theory. Even using these specific periods, we can test and find differences in performance measures between adopting and nonadopting online retailers and between early and late adopting online retailers. Future research could shed ample light on the nature and benefits of adoption and examine this process over longer periods to assess the full diffusion life cycle for a specific capability. We also acknowledge that the dataset covers a specific time frame (2006-2012), which carries the limitations of the technologies applied at that time. This may be a limitation of generalizability for the specific functionalities examined, but our findings support generalizability at the capability level. However, it is an opportunity for future research to scrutinize the findings in the light of new emerging technologies.

Finally, we recognize that e-commerce capabilities operate as part of a larger system and that there are likely synergistic effects from combinations of capabilities we cannot capture in our analyses. For example, infrastructure improvements may optimize the functionality of other e-commerce capabilities, and the combination of infrastructure capabilities with other consumerfacing capabilities may produce the greatest advantages. Overall, we suggest conducting more extensive research to explore these possible relationships in future. 


\section{References}

[1] M.A. Mahmood, M. Siponen, F.J. López, A. Vance, Measuring electronic commerce technology-enabled business value: an empirical investigation, J. Organ. Comput. Electron. Commer. 22 (3) (2012) 256-279.

[2] K. Zhu, The complementarity of information technology infrastructure and e-commerce capability: a resource-based assessment of their business value, J. Manag. Inf. Syst. 21 (1) (2004) 167-202.

[3] K. Zhu, K.L. Kraemer, E-commerce metrics for net-enhanced organizations: assessing the value of e-commerce to firm performance in the manufacturing sector, Inf. Syst. Res. 13 (3) (2002) 275-295.

[4] A. Bhatnagar, A. Sen, A.P. Sinha, Providing a window of opportunity for converting eStore visitors, Inf. Syst. Res. 28 (1) (2016) 22-32.

[5] A. Ayanso, R. Yoogalingam, Profiling retail web site functionalities and conversion rates: a cluster analysis, Int. J. Electron. Commer. 14 (1) (2009) 79-113.

[6] E. Babakus, C.C. Beinstock, J.R. Van Scotter, Linking perceived quality and customer satisfaction to store traffic and revenue growth, Decis. Sci. 35 (4) (2004) 713-737.

[7] J.W. Palmer, Web site usability, design, and performance metrics, Inf. Syst. Res. 13 (2) (2002) 151-167.

[8] P. Sheldon, M. Yamnitsky, Z.D. Widger, A. Hoar, R. Katz, US Commerce Platform Technology and Services Forecast, 2014 To 2019. Forrester, 2015.

[9] E-Commerce Software Market Size, Industry Report 2020-2027, Grand View Research, 2020.

[10] D.W. Straub, D.L. Hoffman, B.W. Weber, C. Steinfield, Toward new metrics for netenhanced organizations, Inf. Syst. Res. 13 (3) (2002) 227-238.

[11] R. Kohli, V. Grover, Business value of IT: an essay on expanding research directions to keep up with the times. J. Assoc. Inf. Syst. 9 (1) (2008) 23-39.

[12] D.V. Parboteeah, J.S. Valacich, J.D. Wells, The influence of website characteristics on a consumer's urge to buy impulsively, Inf. Syst. Res. 20 (1) (2009) 60-78.

[13] J. Hulland, M.R. Wade, K.D. Antia, The impact of capabilities and prior investments on online channel commitment and performance. J. Manag. Inf. Syst. 23 (4) (2007) 109142.

[14] V. Venkatesh, J.Y. Thong, X. Xu, Unified theory of acceptance and use of technology: a synthesis and the road ahead. J. Assoc. Inf. Syst. 17 (5) (2016) 328-376.

[15] T.C. Powell, A. Dent-Micallef, Information technology as competitive advantage: the role of human, business, and technology resources, Strateg. Manag. J. 18 (5) (1997) 375405.

[16] E.M. Rogers, The Diffusion of Innovations, vol. 5, The Free Press, New York, 2003.

[17] B. Gu, J. Park, P. Konana, Research note-the impact of external word-of-mouth sources on retailer sales of high-involvement products, Inf. Syst. Res. 23 (1) (2012) 182-196.

[18] S. Wang, H. Cavusoglu, Z. Deng, Early mover advantage in e-commerce platforms with low entry barriers: the role of customer relationship management capabilities, Inf. Manag. 53 (2) (2016) 197-206.

[19] R.R. Sides, M. Marsh, D. Hobbs, B. Furman, The Future of Retail Metrics. Deloitte Development LLC. 2019. https://www2.deloitte.com/us/en/pages/consumerbusiness/articles/future-of-retail-metrics.html. (accessed 6 August 2021). 
[20] InternetRetailer. Top 500 Guide. 2006-2012.

https://www.digitalcommerce360.com/internet-retailer/. (accessed 5 August 2021).

[21] R. Olbrich, C. Holsing, Modeling consumer purchasing behavior in social shopping communities with clickstream data, Int. J. Electron. Commer. 16 (2) (2011) 15-40.

[22] W.W. Moe, An empirical two-stage choice model with varying decision rules applied to internet clickstream data, J. Market. Res. 43 (4) (2006) 680-692.

[23] R.E. Bucklin, C. Sismeiro, A model of web site browsing behavior estimated on clickstream data, J. Market. Res. 40 (3) (2003) 249-267.

[24] R. Kohli, S. Devaraj, Measuring information technology payoff: a meta-analysis of structural variables in firm-level empirical research, Inf. Syst. Res. 14 (2) (2003) 127145.

[25] R. Sabherwal, A. Jeyarah, Information technology impacts on firm performance: an extension of Kohli and Devaraj (2003). MIS Q. 39 (4) (2015) 809-836.

[26] Y. Liu, Y. Lee, A.N.K. Chen, How IT wisdom affects firm performance: an empirical investigation of 15-year US panel data, Decis. Supp. Syst. 133 (2020) 1-11.

[27] T.J.V. Saldanha, D. Lee, S. Mithas, Aligning information technology and business: the differential effects of alignment during investment planning, delivery, and change, Inf. Syst. Res 31 (4) (2020) 1260-1281.

[28] A.L. Meroño-Cerdan, P. Soto-Acosta, External web content and its influence on organizational performance, Eur. J. Inf. Syst. 16 (1) (2007) 66-80.

[29] Y. Feng, K.H. Lim, Y. Qian, B. Feng, System dynamics modeling for information systems research: theory development and practical application, MIS Q. 42 (4) (2018) 1303-1329.

[30] J. Braojos, J. Benitez, F.J. Llorens Montes, L. Ruiz, Impact of IT integration on the firm's knowledge absorption and desorption, Inf. Manag. 57 (7) (2020) 103290.

[31] P. Mikalef, M. Boura, G. Lekakos, J. Krogstie, The role of information governance in big data analytics driven innovation, Inf. Manag. 57 (7) (2020) 103361.

[32] S. Wang, H. Cavusoglu, Small and medium-sized manufacturer performance on third party B2B electronic marketplaces: the role of enabling and IT capabilities, Decis. Supp. Syst. 79 (2015) 184-194.

[33] K.S. Han, M.H. Noh, Critical failure factors that discourage the growth of electronic commerce, Int. J. Electron. Commer. 4 (2) (1999) 25-43.

[34] K. Chang, J. Jackson, V. Grover, E-commerce and corporate strategy: an executive perspective, Inf. Manag. 40 (7) (2003) 663-675.

[35] Y. Zhuang, A.L. Lederer, A resource-based view of electronic commerce, Inf. Manag. 43 (2) (2006) 251-261.

[36] H. Van der Heijden, Measuring IT core capabilities for electronic commerce, J. Inf. Technol. 16 (1) (2001) 13-22.

[37] J. Lin, L. Li, X. Luo, J. Benitez, How do agribusinesses thrive through complexity? The pivotal role of e-commerce capability and business agility, Decis. Supp. Syst. 135 (2020) 113342.

[38] J. Braojos, J. Benitez, J. Llorens, How do social commerce-IT capabilities influence firm performance? Theory and Empirical Evidence. Inf. Manag. 56 (2) (2019) 155-171.

[39] K. Zhu, K.L. Kraemer, Post-adoption variations in usage and value of e-business by organizations: cross-country evidence from the retail industry, Inf. Syst. Res. 16 (1) (2005) 61-84. 
[40] J. Luo, M. Fan, H. Zhang, Information technology, cross-channel capabilities, and managerial actions: evidence from the apparel industry, J. Assoc. Inf. Syst. 17 (5) (2016) 308-327.

[41] J. Barney, Firm resources and sustained competitive advantage, J. Manag. 17 (1) (1991) 99-120.

[42] D.J. Teece, G. Pisano, A. Shuen, Dynamic capabilities and strategic management, Strateg. Manag. J. 18 (7) (1997) 509-533.

[43] M. Wade, J. Hulland, The resource-based view and information systems research: review, extension, and suggestions for future research, MIS Q. 28 (1) (2004) 107-142.

[44] A.S. Bharadwaj, A resource-based perspective on information technology capability and firm performance: an empirical investigation, MIS Q. 24 (1) (2000) 169-196.

[45] S. Nevo, M.R. Wade, The formation and value of IT-enabled resources: antecedents and consequences of synergistic relationships, MIS Q. 34 (1) (2010) 163-183.

[46] W.L. Yeung, Functional characteristics of commercial web sites: a longitudinal study in Hong Kong, Inf. Manag. 41 (4) (2004) 483-495.

[47] T. Harrison, K. Waite, A time-based assessment of the influences, uses and benefits of intermediary website adoption, Inf. Manag. 43 (8) (2006) 1002-1013.

[48] R.C. Beatty, J.P. Shim, M.C. Jones, Factors influencing corporate website adoption: a time-based assessment, Inf. Manag. 38 (6) (2001) 337-354.

[49] T. Stratopoulos, Duration of competitive advantage due to emerging technology adoption, in UKAIS (2016).

[50] E. Von Hippel, "Sticky information" and the locus of problem solving: implications for innovation, Manag. Sci. 40 (4) (1994) 429-439.

[51] R.Z. Finney, J.E. Lueg, N.D. Campbell, Market pioneers, late movers, and the resourcebased view (RBV): a conceptual model, J. Bus. Res. 61 (9) (2008) 925-932.

[52] M.E. Porter, Strategy and the internet, Harv. Bus. Rev. 79 (2001) 63-78.

[53] R. Varadarajan, M.S. Yadav, V. Shankar, First-mover advantage in an internet-enabled market environment: conceptual framework and propositions, J. Acad. Market. Sci. 36 (3) (2008) 293-308.

[54] G. Häubl, V. Trifts, Consumer decision making in online shopping environments: the effects of interactive decision aids, Market. Sci. 19 (1) (2000) 4-21.

[55] S.L. Jarvenpaa, P.A. Todd, Consumer reactions to electronic shopping on the world wide web, Int. J. Electron. Commer. 1 (2) (1996) 59-88.

[56] J. Benitez, Y. Chen, S.H. Teo Thompson, A. Ajamieh, Evolution of the impact of ebusiness technology on operational competence and firm profitability: a panel data investigation, Inf. Manag. 55 (1) (2018) 120-130.

[57] A.H. Crespo, I.R. del Bosque, The influence of the commercial features of the internet on the adoption of e-commerce by consumers, Electron. Commer. Res. Appl. 9 (6) (2010) 562-575.

[58] T. Che, Z. Peng, K.H. Lim, Z. Hua, Antecedents of consumers' intention to revisit an online group-buying website: a transaction cost perspective, Inf. Manag. 52 (5) (2015) 588-598.

[59] X. Luo, J. Zhang, W. Duan, Social media and firm equity value, Inf. Syst. Res. 24 (1) (2013) 146-163.

[60] X. Luo J. Zhang, How do consumer buzz and traffic in social media marketing predict the value of the firm? J. Manag. Inf. Syst. 30 (2) (2013) 213-238. 
[61] R. Rishika, A. Kumar, R. Janakiraman, R. Bezawada, The effect of customers' social media participation on customer visit frequency and profitability: an empirical investigation, Inf. Syst. Res. 24 (1) (2013) 108-127.

[62] N. Thongpapanl, A.R. Ashraf, Enhancing online performance through website content and personalization, J. Comput. Inf. Syst. 52 (1) (2011) 3-13.

[63] D. Bruce, W.F. Fox, L. Luna, E-tailer sales tax nexus and state tax policies, Natl. Tax J. 68 (3S) (2015) 735-766.

[64] F.P. Karimov, M. Brengman, An examination of trust assurances adopted by top internet retailers: unveiling some critical determinants, Electron. Comm. Res. 14 (4) (2014) 459496.

[65] B. McWilliams, Money-back guarantees: helping the low-quality retailer, Manag. Sci. 58 (8) (2012) 1521-1524.

[66] P.J. Danaher, G.M. Mullarkey, S. Essegaier, Factors affecting website visit duration: a cross-domain analysis, J. Market. Res. 43 (2) (2006) 182-194.

[67] P. Chatterjee, D.L. Hoffman, T.P. Novak, Modeling the clickstream: implications for web-based advertising efforts, Market. Sci. 22 (4) (2003) 520-541.

[68] C. Sismeiro, R.R. Bucklin, Modeling purchase behavior at an e-commerce web site: a task completion approach, J. Market. Res. 41 (2004) 306-323.

[69] I. Petina, A. Amialchuk, D.G. Taylor, Exploring effects of online shopping experiences on browser satisfaction and e-tail performance, Int. J. Retail Distrib. Manag. 39 (4) (2011) 742-758. 
Appendix A: Description of E-commerce capabilities

\begin{tabular}{ll} 
Category & Description \\
\hline Information &
\end{tabular}

Product comparisons

Syndicated content

\section{$\underline{\text { Transaction }}$}

Catalog quick order

Deferred payment

PayPal express checkout

\section{$\underline{\text { Interaction }}$}

Frequent buyer program

Personalization

\section{$\underline{\text { Infrastructure }}$}

Content delivery

CRM

E-commerce platform

Web performance monitor
Allows customers to compare features of two or more products.

Provides content from third parties that is updated automatically without the website's intervention (e.g., news, stock prices, etc.).

Allows customers to expedite a purchase by entering an item's catalog number online.

Allows customers to delay payment for some time.

Service that interfaces with PayPal to offer an expedited payment and checkout process.

Offers a program that rewards repeat customers by offering discounts or redeemable points.

Provides customized features and contents in accordance with visitors' profiles when they visit the site (usually requires registration).

Third-party service that supports the delivery or distribution of purchased media content such as audio, video, software, and video games.

Manages the company's interaction with current and future customers using technology to organize, automate, and synchronize sales, marketing, customer service, and technical support.

Uses a complete online retail store application that provides various ecommerce capabilities and functions in one integrated system.

Uses a service that assesses website availability and speed, to ensure websites display content as quickly as possible.

Note: This Table presents definitions of the 11 e-commerce capabilities whose adoption has changed from one diffusion phase to the next during the sample period and which are examined in regression analyses. Please see the online appendix for definitions for all $44 \mathrm{e}$-commerce capabilities assessed. 